\title{
Antarctic and Southern Ocean Surface Temperatures in CMIP5 Models in the Context of the Surface Energy Budget*
}

\author{
DAVID P. SCHNEIDER \\ Climate and Global Dynamics Laboratory, National Center for \\ Atmospheric Research, ${ }^{+}$Boulder, Colorado \\ DAVID B. REUSCH \\ Department of Earth and Environmental Science, New Mexico Institute of Mining and \\ Technology, Socorro, New Mexico
}

(Manuscript received 20 June 2015, in final form 7 December 2015)

\begin{abstract}
This study examines the biases, intermodel spread, and intermodel range of surface air temperature (SAT) across the Antarctic ice sheet and Southern Ocean in 26 structurally different climate models. Over the ocean $\left(40^{\circ}-60^{\circ} \mathrm{S}\right)$, an ensemble-mean warm bias peaks in late austral summer concurrently with the peak in the intermodel range of SAT. This warm bias lags a spring-summer positive bias in net surface radiation due to weak shortwave cloud forcing and is gradually reduced during autumn and winter. For the ice sheet, inconsistencies among reanalyses and observational datasets give low confidence in the ensemble-mean bias of SAT, but a small summer warm bias is suggested in comparison with nonreanalysis SAT data. The ensemble mean hides a large intermodel range of SAT, which peaks during the summer insolation maximum. In summer on the ice sheet, the SAT intermodel spread is largely associated with the surface albedo. In winter, models universally exhibit a too-strong deficit in net surface radiation related to the downward longwave radiation, implying that the lower atmosphere is too stable. This radiation deficit is balanced by the transfer of sensible heat toward the surface (which largely explains the intermodel spread in SAT) and by a subsurface heat flux. The winter bias in downward longwave radiation is due to the longwave cloud radiative effect, which the ensemble mean underestimates by a factor of 2 . The implications of these results for improving climate simulations over Antarctica and the Southern Ocean are discussed.
\end{abstract}

\section{Introduction}

Several aspects of observed climate changes over the Southern Ocean and Antarctica have been challenging to explain, lowering confidence in projections of future changes. For example, there is no single agreed-upon explanation for the increase in Antarctic sea ice extent during the satellite era (e.g., Holland 2014; Fan et al.

\footnotetext{
* Supplemental information related to this paper is available at the Journals Online website: http://dx.doi.org/10.1175/JCLI-D-15-0429.s1.

${ }^{+}$The National Center for Atmospheric Research is sponsored by the National Science Foundation.
}

Corresponding author address: David P. Schneider, Climate and Global Dynamics Laboratory, National Center for Atmospheric Research, Box 3000, Boulder, CO 80307-3000.

E-mail: dschneid@ucar.edu
2014; Bintanja et al. 2013), little consensus on the response of the Antarctic Circumpolar Current (ACC) to the observed increase in the westerly winds (e.g., Boning et al. 2008; Dufour et al. 2012; Meijers 2014), and divergent views about the relative roles of stratospheric ozone depletion and tropical SSTs in driving these wind changes (e.g., Thompson et al. 2011; Ding et al. 2012; Staten et al. 2012; Schneider et al. 2015).

Climate models are the key tools for addressing these problems, yet numerous biases in their simulations of sea ice, winds, clouds, and many other aspects of the climate of Antarctica and the Southern Ocean have been identified. Many of these biases are outside the range expected from internal variability or observational uncertainty (e.g., Mahlstein et al. 2013; Zunz et al. 2013; Meijers 2014; Sallée et al. 2013). Surface air temperature (SAT) is perhaps the most common variable used to describe the climate of a region and to 
characterize climate change. The most extensive region of positive biases in SAT in the multimodel mean of current-generation models occurs across the Southern Ocean (Flato et al. 2013), consistent with the prevalent warm and negative density biases of the Southern Ocean water masses in these models (Sallee et al. 2013). It has been suggested that the oceanic warm bias stems from excessive downward shortwave radiation related to shortcomings in cloud simulations (e.g., Bodas-Salcedo et al. 2012), but little work has been done to quantify this connection. These warm biases may be linked to the general inability of most models to simulate the observed increase in Antarctic sea ice extent during the satellite era (e.g., Turner et al. 2013; Hobbs et al. 2015). Over the ice sheet, even less is known about the nature of SAT biases, their connections with clouds and radiation biases, or their possible links with biases in the surrounding ocean.

As suggested previously, the bias in SAT over the ocean is likely a symptom of problems in the surface energy budget, which in turn has important implications for simulations of climate dynamics and the response to climate change. Over the Southern Ocean and Antarctica, the energy budgets are highly coupled with the large-scale atmospheric (e.g., Parish and Bromwich 2007; Previdi et al. 2013) and oceanic circulations (e.g., Marshall and Speer 2012; Sallée et al. 2013). With its high albedo, thin overlying atmosphere, and surface that emits almost as a blackbody, the Antarctic ice sheet is an important heat sink in the global climate system (e.g., van den Broeke 2004). The Southern Ocean, driven by wind, heat, and freshwater fluxes, plays a key role in the climate system by regulating the absorption and global redistribution of heat and carbon (e.g., Marshall and Speer 2012; Rintoul and Naveira Garabato 2013).

The main objective of this paper is to evaluate climatological SAT biases across Antarctica and the Southern Ocean in the climate models participating in phase 5 of the Coupled Model Intercomparison Project (CMIP5; Taylor et al. 2012). We place the annual cycle of the SAT and its bias in the context of the surface energy budget, separating the analysis into ocean and land domains. The surface energy budget perspective exposes a number of physical processes and properties simultaneously, relating to clouds, surface albedo, heat fluxes, and other factors, providing a broad view of model performance and how these processes fit together.

An additional motivation of this study is to enable the informed selection of climate models to use as boundary conditions for regional models. Many climate change impacts, such as surface melting, occur at spatial scales smaller than the typical resolution of a global climate model, and there may be added value in assessing these impacts using simulations of regional models, which offer finer spatial resolution. However regional simulations are dependent on the lateral boundary conditions from global models, which may contain errors in the large-scale climate (e.g., Pielke and Wilby 2012) that regional simulations may not be able to eliminate (e.g., Ekström et al. 2015).

A useful metric of model performance for the largescale climate over Antarctica and the Southern Ocean that our analysis leads to, particularly for summer, is the absorbed solar radiation (ASR), the difference of incoming and outgoing shortwave radiation at the top of the atmosphere (TOA) (e.g., Trenberth and Fasullo 2010). Locally in Antarctica and the Southern Ocean, the ASR relates to cloud reflectance, sea ice cover, and ice sheet surface albedo, and this quantity broadly captures model skill in simulating these quantities, as well as properties that are fundamentally linked, including the SAT. ASR is also influenced by aerosols and by atmospheric absorption of shortwave radiation by gasses such as stratospheric ozone. For the purposes of this study, we focus on the dominant role of cloud forcing and ice sheet albedo in explaining the intermodel spread of ASR over the Southern Ocean and Antarctic continent, respectively. Detailed analyses of the various contributions to the mean ASR in observations or individual models are provided in the literature (e.g., Qu and Hall 2005; Donohoe and Battisti 2011). We emphasize the model performance with respect to austral summer [December-February (DJF)] climate, as this is when some of the largest biases and intermodel differences in SAT occur, and when the shortwave-related biases that have been noted previously are most strongly expressed. In terms of climate impacts, summer is when the cryosphere is close to the melting threshold, and when the ocean receives the energy that is released to the atmosphere in winter or redistributed by currents.

\section{Data and methods}

This study evaluates output from 26 coupled models contributing data to the CMIP5 multimodel archive (Table 1). Monthly mean output was obtained from the first ensemble member of the 1850-2005 historical (twentieth century) experiment (Taylor et al. 2012). The models were selected on the criteria of data availability and the requirement that they be structurally different. This means that at least one of the major component models making up the coupled model must be physically different from the other models. Physical differences range from horizontal resolution to the physical parameterizations of major processes. Models that include 


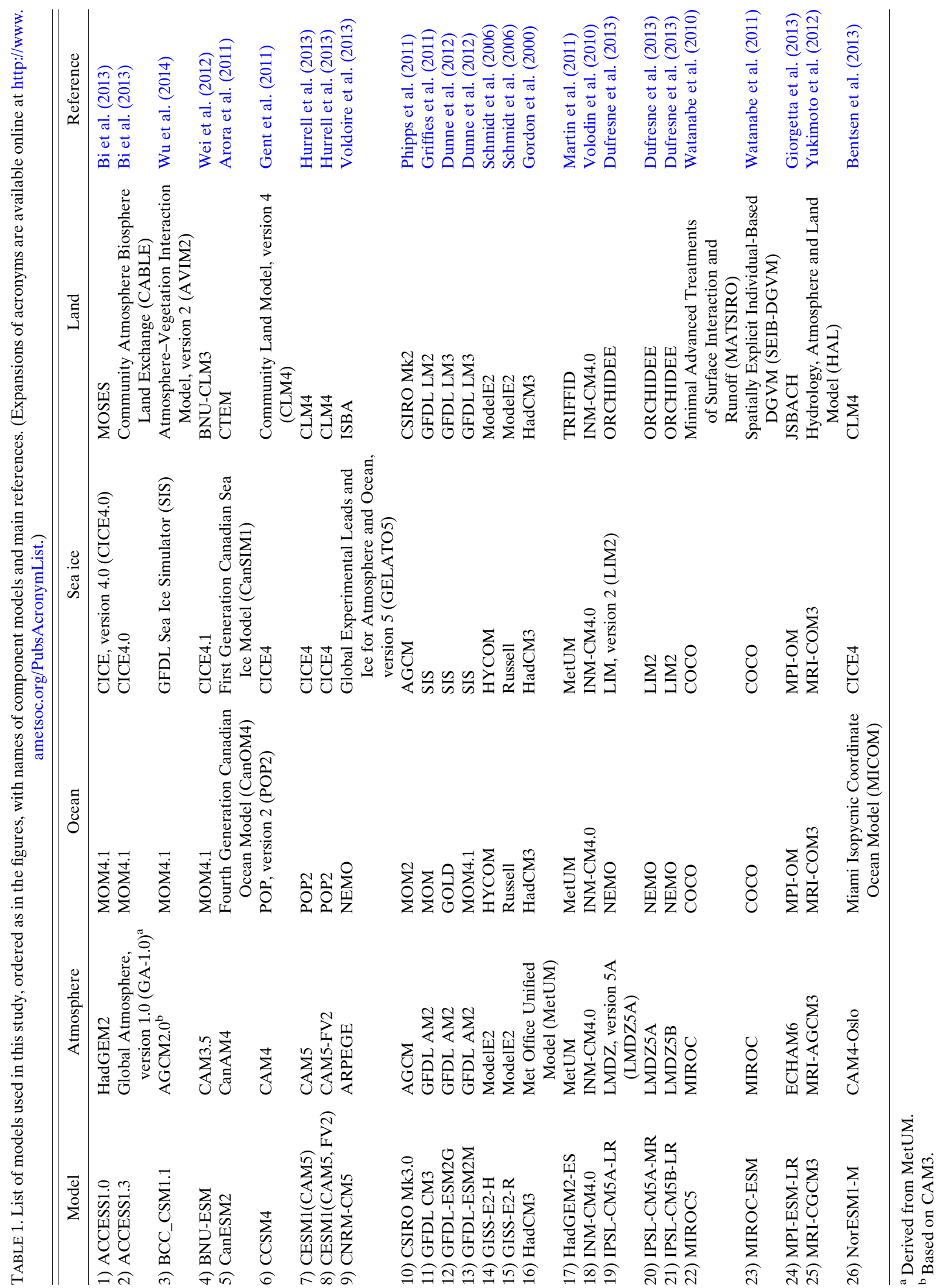


TABLE 2. List of CMIP5 variables used in this study with corresponding observational datasets.

\begin{tabular}{|c|c|c|}
\hline Variable & CMIP5 variable names & Observations \\
\hline Surface air temperature & $\operatorname{tas}$ & ERAI, MERRA, and UDEL \\
\hline Surface longwave radiation & rlds, rlus, rldscs, and rluscs & CERES-EBAF \\
\hline Surface shortwave radiation & rsus, rsds, rsuscs, and rsdscs & CERES-EBAF \\
\hline Surface sensible heat flux & hfls & - \\
\hline Surface latent heat flux & hfss & - \\
\hline TOA longwave radiation & rlut and rlutcs & CERES-EBAF \\
\hline TOA shortwave radiation & rsut, rsdt, and rsutcs; & CERES-EBAF \\
\hline Land area fraction & sftlf & - \\
\hline
\end{tabular}

interactive biogeochemistry or carbon cycling but are otherwise the same as their parent models are not considered structurally different for the purposes of this study. Nonetheless, the remaining population of models still has substantial overlap because component models are shared across modeling centers. For example, the Community Land Model (CLM) is used by CESM1 (CAM5) and CCSM4, as well as by NorESM1-M (Table 1). Similarly, the MOM, version 4.1 (MOM4.1) is the ocean model used in several CMIP5 models (Table 1). On the one hand, the substantial overlap among CMIP5 models increases confidence that common biases are systematic or structural, that is, relating to model physics rather than to internal variability. On the other hand, it reduces the independence of solutions and degrees of freedom that may be desired or expected in the large CMIP5 database.

This analysis uses 16 variables from the CMIP5 output; their CMIP5 variable names are given in Table 2, along with the comparable observational datasets. For each variable, we compute monthly and seasonal climatologies based on 20 years of monthly means for 1981-2000. The least squares linear trend for 1980-2000 is removed from the monthly or seasonal mean values at each grid point. Spatial averages are calculated over two domains on the basis of a $1^{\circ} \times 1^{\circ}$ latitude-longitude land-sea mask. This common land-sea mask is regridded to each model's native resolution by bilinear interpolation, and the regridded masks are used to delineate the land and ocean grid points. The Antarctic ice sheet (AIS) is defined as the land grid points over $60^{\circ}-$ $90^{\circ} \mathrm{S}$. Note that this includes the grounded ice sheet only, not the major ice shelves. The area defined as the AIS for selected models is indicated in the supplemental material (see Fig. S1 therein). The regridded masks are much more consistent with each other than are the models' native masks (Fig. S2 in the supplemental material). The Southern Ocean refers to the ocean grid points over $40^{\circ}-60^{\circ} \mathrm{S}$. Spatial averages are based on weighting each grid point by the cosine of its latitude. The ensemble-mean biases are calculated as the mean of the models' individual biases based on comparing the individual spatial averages to observations. The ensemble-mean fields, presented in map form, are based on regridding each model field to a common $1^{\circ} \times 1^{\circ}$ resolution, then averaging across these regridded fields. We largely ignore the seasonal sea ice zone between $60^{\circ} \mathrm{S}$ and the Antarctic coast, as the ice cover is quite variable in time and across models, and has been the focus of a number of recent studies (e.g., Turner et al. 2013; Mahlstein et al. 2013; Zunz et al. 2013; Hobbs et al. 2015).

For observations, we utilize land and ocean surface air temperatures at $2 \mathrm{~m}$ from the ERA-Interim (ERAI) data (Dee et al. 2011), and the Modern-Era Retrospective Analysis for Research Applications (MERRA; Rienecker et al. 2011). Both datasets have similar climatology over the ocean but, as discussed below, there are significant differences over land. The problems with reanalysis datasets over Antarctica (e.g., Cullather and Bosilovich 2012; Bracegirdle and Marshall 2012) lead us to also consider the gridded monthly time series of land SAT in the University of Delaware dataset (UDEL) version 3.01, which incorporates a network of Antarctic automated weather stations in addition to Antarctic station data in the Global Historical Climatology Network (Matsuura and Wilmott 2012). The ERAI, MERRA, and UDEL data are detrended and spatially averaged in the same way as the model output.

TOA and surface radiative fluxes are taken from CERES-EBAF, version 2.7 (Loeb et al. 2009, 2012). The CERES net TOA fluxes are constrained to be consistent with ocean heat uptake, ice melt, and atmospheric warming, while the surface fluxes are consistent with the TOA fluxes (Loeb et al. 2009, 2012). CERES-EBAF climatologies matching the dates of the model output can only be obtained for 2001-05. Inspection of time series from CERES-EBAF suggests that averaging over a longer time period is more important than exactly matching the time period of the model data, as the longterm trends are small in comparison with the interannual variability (see Trenberth et al. 2015). To form a stable 
climatology, the period 2001-10 is used for CERESEBAF. The CERES-EBAF data are processed in the same way as the model output, although regridding was not necessary as the data were provided on a $1^{\circ} \times 1^{\circ}$ grid.

Five derived quantities are computed from a combination of variables from both model output and observational data. First, ASR is the difference of the TOA incoming and outgoing shortwave radiation (rsdt - rsut in the CMIP5 notation from Table 2). Second, shortwave cloud forcing (SWCF) modifies the upwelling term in the ASR; it is the clear-sky minus all-sky upwelling shortwave radiation (rsutcs - rsut, using the CMIP5 notation from Table 2). Third, we calculate the clear-sky surface albedo as the ratio of the downward and upward fluxes of shortwave radiation under clear-sky conditions (rsdscs/rsuscs, using the CMIP5 notation from Table 2). All-sky surface albedo is similarly calculated, using the respective all-sky radiative fluxes. Finally, the longwave cloud radiative effect at the surface $\left(\mathrm{CRE}-\mathrm{LW}_{s}\right)$, described in Stephens et al. (2012a), is the difference of the all-sky and clear-sky downward longwave radiative fluxes (rlds - rldscs, using the CMIP5 notation from Table 2).

While we discuss model biases, that is, the quantitative differences between a simulated climate field and the corresponding observed climate field, we place greater emphasis on the spread across models (or intermodel spread or just model spread), also referred to as structural uncertainty (e.g., Masson and Knutti 2011). Some of the motivation for this arises from observational uncertainty, which is especially large over Antarctica and the Southern Ocean, making it difficult to pin down the models' biases. More importantly, an understanding of model spread can enable modelers to trace model differences in a simulated quantity to the physics that are different among models. We will also use the term intermodel range to refer to the difference between the maximum and minimum model values for a given climatological variable for a particular region and time period. In other words, the range is the difference of the extreme values, while the spread is a vector consisting of each model's value of a simulated quantity. The significance of relationships between two variables (correlation of model spread) is assessed by a two-tailed Student's $t$ test with adjustment for degrees of freedom based on lag-1 autocorrelation. Each correlation discussed below or presented in the tables is significant at the $95 \%$ level or above, unless otherwise noted.

The following results and discussion sections begin with section 3, an assessment of the monthly, ensemblemean SAT climatologies and surface radiation budgets in CMIP5 models. These results, together with the sensitivity of the cryosphere to climate change in summer, motivate a closer evaluation of the SAT simulations in summer, presented in section 4. Section 5 discusses the surface energy budgets in the summer, winter [June-August (JJA)] and the annual mean. Finally, section 6 summarizes and discusses the results of the preceding sections.

\section{Ensemble-mean climatology and biases in SAT and radiation}

Distinctive characters of the seasonal cycles of SAT over the AIS and Southern Ocean are evident in the CMIP5 multimodel mean. On land (Fig. 1a), a brief but well-defined seasonal temperature maximum occurs in December and January, closely following the peak in insolation at the solstice. The cold season begins in March and lasts for several months without a distinct temperature minimum, a defining characteristic of the coreless winter (e.g., Warren 1996). Over the ocean (Fig. 1b), the seasonal temperature cycle is almost symmetric, with a 3-month maximum in January through March and a minimum in July through September. The thermal lag with respect to the peak insolation is about 2 months, with the maximum temperature reached in February. The range of the seasonal SAT cycle on the AIS is about $25^{\circ} \mathrm{C}$, about 5 times greater than over the ocean.

Figure 2 presents the seasonal cycle of the ensemblemean bias, intermodel range, and spread in SAT. The ocean SAT bias with respect to ERAI (gray dashed line on Fig. 2a) increases from near zero in the spring to its maximum in February of about $1^{\circ} \mathrm{C}$. The bias gradually tapers off as the autumn and winter progress, giving the curve a seasonally asymmetric shape. The ocean warm bias during summer and autumn is of similar magnitude and seasonality if MERRA is the reference data instead of ERAI. In late autumn and winter, the models are slightly less warm-biased with respect to MERRA than to ERAI. The intermodel range of SAT over the ocean is also largest in February, with a secondary maximum during the late winter and early spring (Fig. 2b). Some of this secondary maximum is associated with the sea ice edge, which varies substantially across models (Zunz et al. 2013). To reduce the influence of the ice edge, Fig. $2 b$ also shows the intermodel range if the domain is restricted to $40^{\circ}-55^{\circ} \mathrm{S}$ instead of $40^{\circ}-60^{\circ} \mathrm{S}$; in this smaller domain, the intermodel range is not as large in the winter. In Fig. 2c, the intermodel spread in SAT for January is correlated with the intermodel spread in all other months. Correlations of greater than 0.9 for December through March imply that the intermodel spread is very similar throughout the summer and early 
a) Land

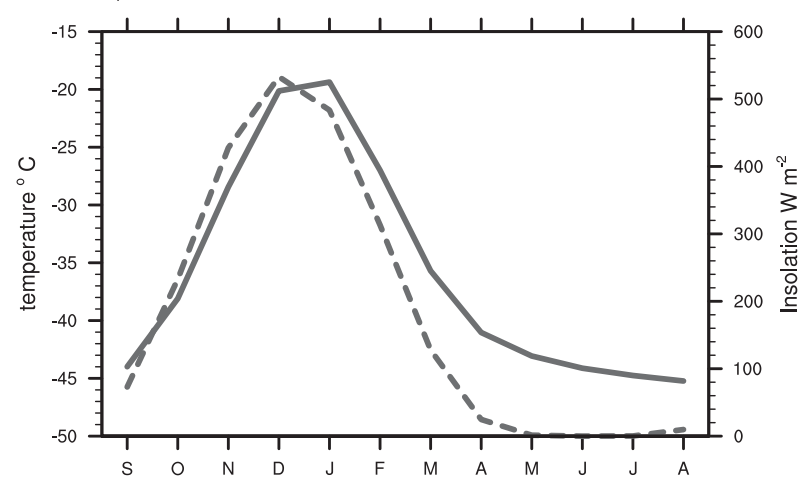

b) Ocean

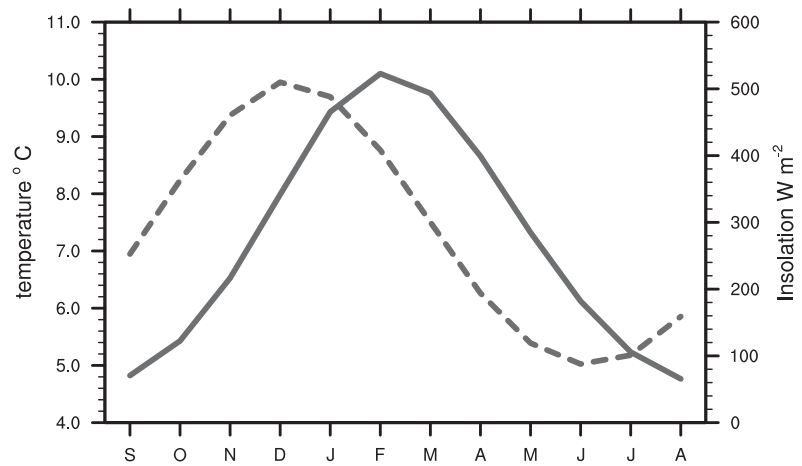

FIG. 1. Ensemble-mean monthly average SAT (solid lines) and insolation (dashed lines) for the (a) AIS and (b) Southern Ocean.

autumn. The correlation gradually declines during the autumn and winter, reaching a minimum in September of approximately 0.65 , with a slightly higher value if the ice edge is avoided. This suggests that even in winter, the model's ocean has memory of the summer conditions that caused it to be relatively warm or cold.

Moving to land, the absolute values and seasonality of the ensemble-mean bias (Fig. 2a) are difficult to constrain because of the disagreement among the reference datasets. With respect to MERRA (red solid line), the models are warm-biased by almost $3^{\circ} \mathrm{C}$ in summer and cold-biased by almost $4^{\circ} \mathrm{C}$ in winter. With respect to ERAI (gray solid line), the models are coldbiased year round, but less cold biased in summer than in winter. In winter, both ERAI and MERRA are warm-biased by up to $10^{\circ} \mathrm{C}$ in portions of the Antarctic interior relative to in situ station data (Bracegirdle and Marshall 2012). In summer, ERAI has a weaker warm bias than in winter (Bracegirdle and Marshall 2012), but MERRA is neutral in some locations such as the South Pole (Bracegirdle and Marshall 2012) and coldbiased across other regions of the ice sheet (Cullather and Bosilovich 2012). The fact that the models are colder with respect to ERAI can be attributed to the a) ensemble-mean bias

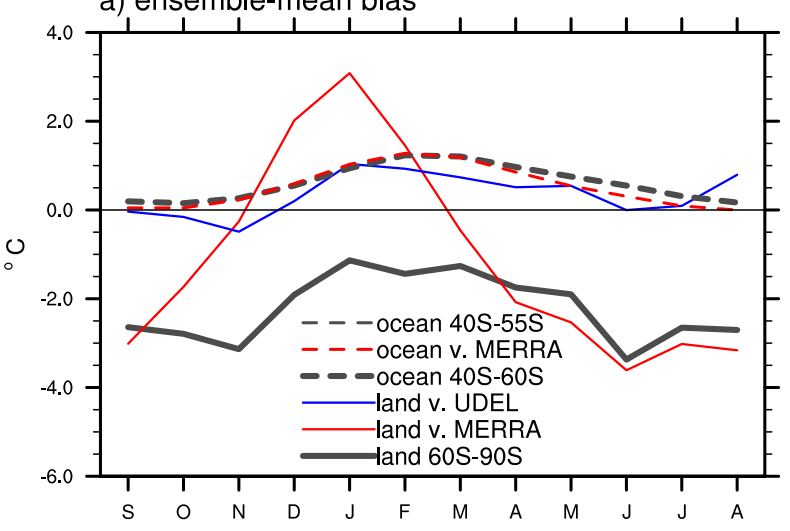

b) inter-model range

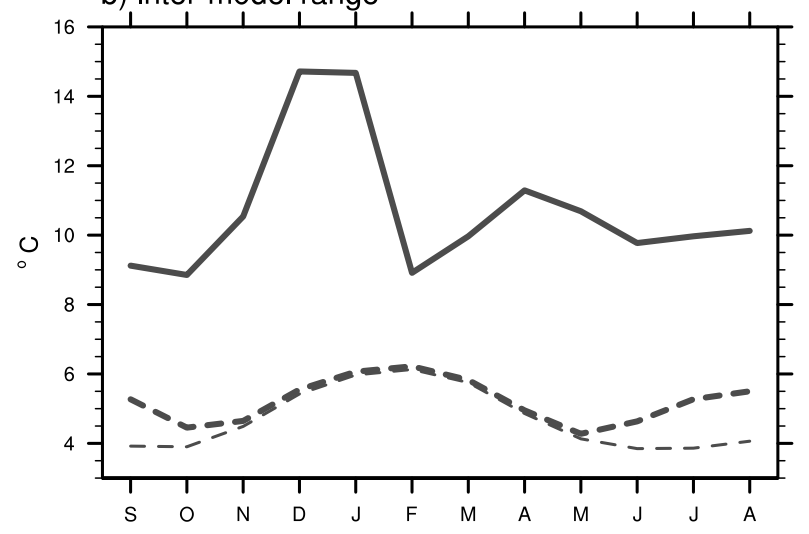

C) January model spread vs. spread in each month

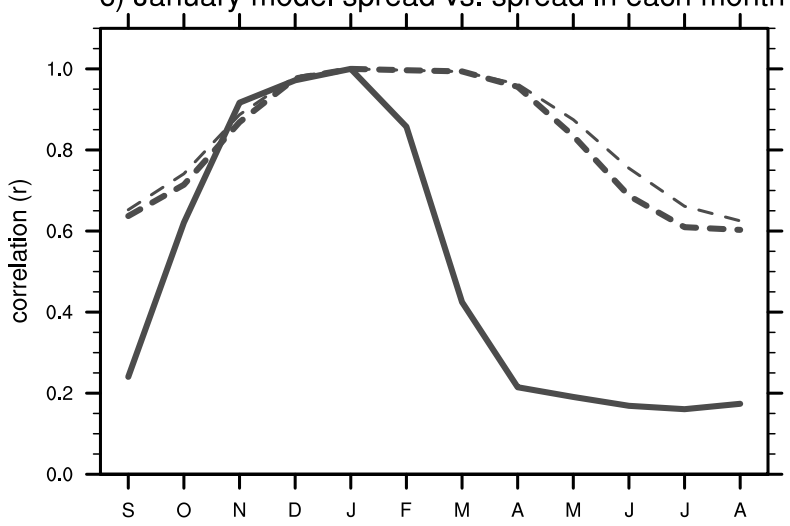

FIG. 2. (a) Ensemble-mean bias of SAT for the AIS and Southern Ocean, (b) intermodel range of SAT for AIS and Southern Ocean, and (c) correlation of model spread in January with model spread in all other months for the AIS and Southern Ocean. In (a), the reference SAT dataset is ERAI unless otherwise indicated in the legend.

warm bias in ERAI over the AIS (Jones and Lister 2014), which persists year-round. The extreme seasonality of the model biases with respect to MERRA may be attributable to its seasonally varying biases, which stem from spurious subsurface heat fluxes (Cullather 
and Bosilovich 2012). To overcome the limitations of the reanalyses, we also compare the ensemble mean with the climatology of UDEL (blue solid line). This comparison suggests a small warm bias in most months with a peak in January and some persistence through the summer and early autumn. Interestingly, the seasonality of the model biases with respect to UDEL parallels the biases with respect to ERAI, but the ERAI biases are offset by $2^{\circ}-3^{\circ} \mathrm{C}$. Given the problems with both reanalyses, the model biases with respect to these datasets should be viewed with caution. For the remainder of this paper, we adopt the climatology from UDEL as the reference SAT dataset for the AIS. We caution that even the observation-based UDEL is limited by the small number of in situ station data in the interior of Antarctica and by the assumptions underlying the interpolation of these station data (Matsuura and Wilmott 2012).

The intermodel range (Fig. 2b) and intermodel spread (Fig. 2c) provide an observation-independent view of the models' SAT simulations. The intermodel range on the AIS peaks during December and January, when the warmest and coldest models are separated by more than $14^{\circ} \mathrm{C}$. The model spread in January is very weakly correlated $(r<0.2)$ with the model spread in the winter months (Fig. 2c). This suggests that the winter intermodel spread in SAT over land is not related to the summer conditions or vice versa. The winter-summer contrast in the model spread of SAT relates to seasonal characteristics of the surface energy budget, which we describe next.

Following van den Broeke et al. (2005) and related work, the net surface energy flux $\mathrm{SEF}_{\text {net }}$ may be defined as the sum of the net radiation $R_{\text {net }}$ and the turbulent heat fluxes $\mathrm{HF}_{\text {net }}$ :

$$
\mathrm{SEF}_{\text {net }}=R_{\text {net }}+\mathrm{HF}_{\text {net }} \text {, }
$$

which can be expanded to

$$
\begin{aligned}
\mathrm{SEF}_{\text {net }}= & \mathrm{SW}_{\text {net }}+\mathrm{LW}_{\text {net }}+\mathrm{HF}_{\text {net }}, \quad \text { or } \\
\mathrm{SEF}_{\text {net }}= & \left(\mathrm{SW}_{d}-\mathrm{SW}_{u}\right)+\left(\mathrm{LW}_{d}-\mathrm{LW}_{u}\right) \\
& +\left(\mathrm{SHF}_{\text {net }}+\mathrm{LHF}_{\text {net }}\right),
\end{aligned}
$$

where $\mathrm{SW}_{d}$ and $\mathrm{SW}_{u}$ are the incident and reflected shortwave radiation fluxes, $\mathrm{LW}_{d}$ and $\mathrm{LW}_{u}$ are the downward and emitted longwave radiation fluxes, $\mathrm{SHF}_{\text {net }}$ and $\mathrm{LHF}_{\text {net }}$ are the sensible and latent heat fluxes, and $\mathrm{SW}_{\text {net }}$ and $\mathrm{LW}_{\text {net }}$ are the net shortwave and longwave radiation. In this convention, positive values of $\mathrm{HF}_{\text {net }}$ and $R_{\text {net }}$ represent an energy transfer from the atmosphere to the land or ocean surface.
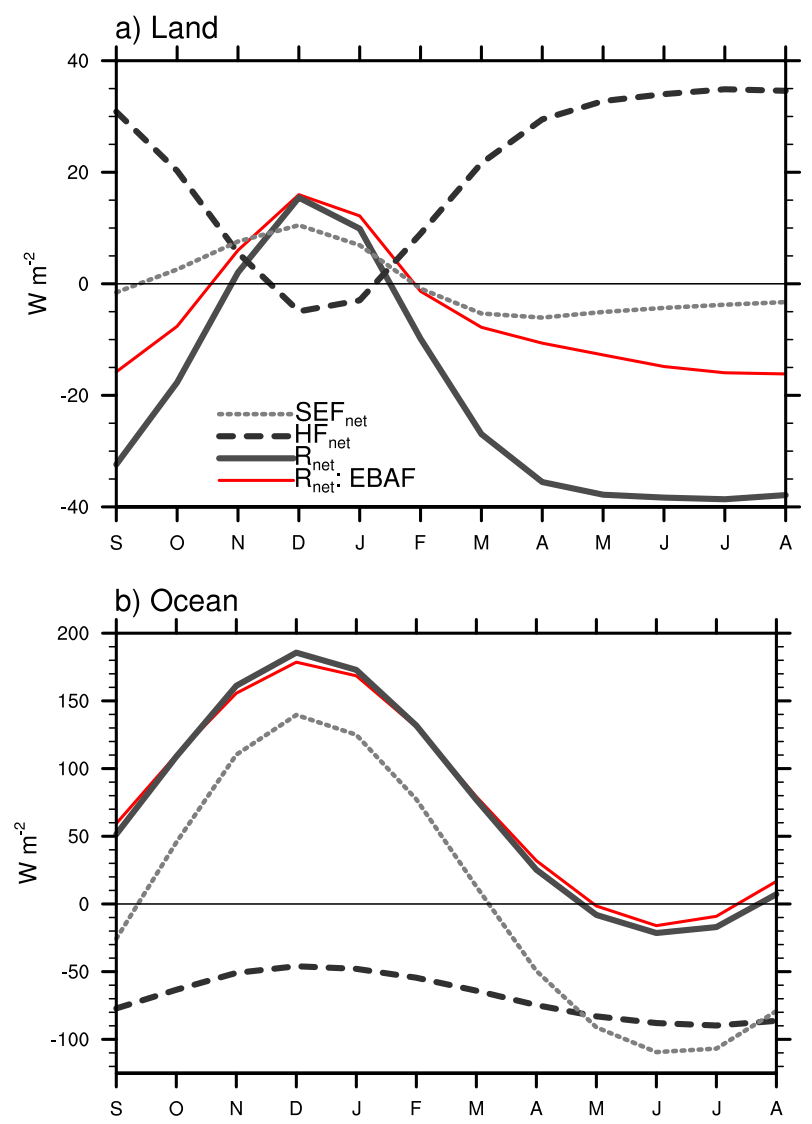

FIG. 3. The monthly, ensemble-mean net surface energy flux and the contributing terms, net radiation and net heat flux, for the (a) AIS and (b) Southern Ocean. Also shown in red is the CERESEBAF net surface radiation.

For a snow surface with a temperature of less than $0^{\circ} \mathrm{C}$, nonzero $\mathrm{SEF}_{\text {net }}$ implies a subsurface conductive heat flux. In Antarctica, monthly values for the conductive heat flux are typically a few watts per meter squared, and annual values are only a few tenths of a watts per meter squared (e.g., van den Broeke et al. 2005). Over most of the continent, $R_{\text {net }}$ and $\mathrm{HF}_{\text {net }}$ (comprising mainly sensible heat) approximately balance, and the annual mean $\mathrm{SEF}_{\text {net }}$ is close to zero (e.g., van den Broeke et al. 2005). Over the ocean, $\mathrm{SEF}_{\text {net }}$ is often referred to as the air-sea heat flux (e.g., Marshall and Speer 2012). Figure 3 shows the terms in Eq. (1) for the ensemble mean for each month, and Fig. 4 expands $R_{\text {net }}$ into its $\mathrm{SW}_{\text {net }}$ and $\mathrm{LW}_{\text {net }}$ components. On land (Fig. 3a), the seasonal cycle of $R_{\text {net }}$, which resembles the intermodel spread in Fig. 2c and the seasonal cycle of SAT in Fig. 1a, has two regimes, distinguished by negative and positive $R_{\text {net }}$. Note that $\mathrm{HF}_{\text {net }}$ is opposite in sign to $R_{\text {net }}$ in nearly all months. In summer, SEF net is slightly positive, implying a heat flux directed into the snowpack. In winter, $\mathrm{SEF}_{\text {net }}$ is negative, as heat is 

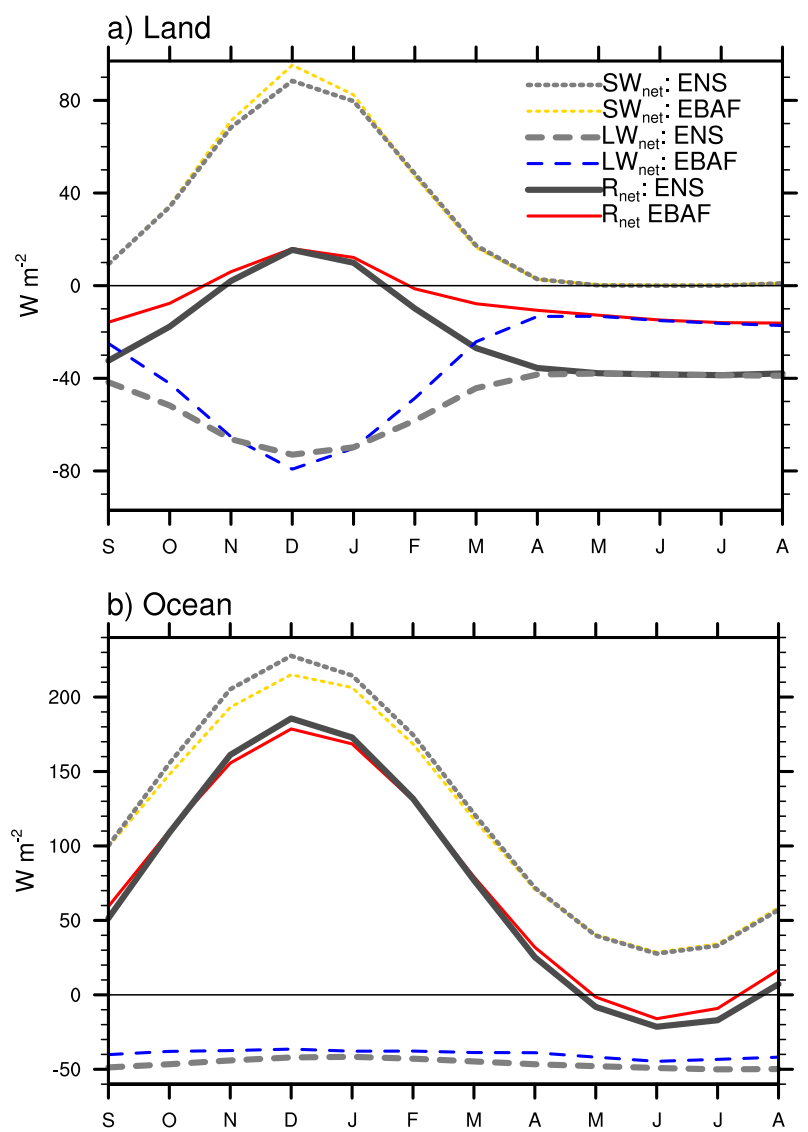

FIG. 4. The monthly, ensemble-mean net radiation and its contributing terms, net shortwave and net longwave radiation are shown as gray lines for the (a) AIS and (b) Southern Ocean. Colored lines correspond to the CERES-EBAF data.

removed from the snowpack. The largest negative $\mathrm{SEF}_{\text {net }}$ is in April when subsurface temperature gradients tend to be greatest (e.g., van den Broeke et al. 2005). For the ocean (Fig. 3b), there is a 3-month period in winter when $R_{\text {net }}$ is negative, and a longer period when the loss associated with $\mathrm{HF}_{\text {net }}$ exceeds $R_{\text {net }}$, resulting in a negative $\mathrm{SEF}_{\text {net }}$ for six months of the year. With respect to biases in $R_{\text {net }}$, the ensemble mean is negatively biased on land in all months, more so in winter than in summer. On the ocean, $R_{\text {net }}$ is positively biased in summer and negatively biased in winter.

Examining the shortwave and longwave components of $R_{\text {net }}$ (Fig. 4), it is clear that the seasonality of $R_{\text {net }}$ is driven by the seasonality of $\mathrm{SW}_{\text {net }}$ over both land and ocean. In response to the increase in $\mathrm{SW}_{\text {net }}$ in spring and early summer, the land heats rapidly (Fig. 1a) and $\mathrm{LW}_{\text {net }}$ becomes more negative (Fig. 4a), resulting in a small positive $R_{\text {net }}$. In winter, when SW net is zero, $R_{\text {net }}$ and $\mathrm{LW}_{\text {net }}$ are equivalent and strongly negative. Over the ocean, the surface temperature does not rise as much during summer, so $\mathrm{LW}_{\text {net }}$ does not change significantly from its winter value, and $R_{\text {net }}$ is much more positive than on land. Additionally, seasonal changes in $\mathrm{LW}_{\text {net }}$ due to surface temperature can be obscured by variations associated with cloud cover (e.g., Bromwich et al. 2012).

Over the ocean, the ensemble mean has too much $\mathrm{SW}_{\text {net }}$ throughout the summer and $R_{\text {net }}$ is positively biased from November through March despite a small but persistent negative bias in $\mathrm{LW}_{\text {net }}$. A simple interpretation of the ensemble-mean ocean warm bias is that it is driven by the excessive shortwave radiation during summer. The largest radiation bias is in December (Fig. 4b), but the largest temperature bias is in February (Fig. 2a), consistent with the ocean's large heat capacity and the thermal lag that is evident in the climatology (Fig. 1b). Although the seasonality of the forcing and the climatological SAT is roughly symmetric (Fig. 1b), the oceanic warm bias has an asymmetric seasonality (Fig. 2a). The gradual reduction of the SAT bias from the autumn through early spring (Fig. 2a) may be explained by the cooling of the ocean surface by longwave emission and surface heat fluxes. Oceanographic processes with a strong seasonality, including upwelling and mixed layer deepening, may also contribute to the seasonal asymmetry of the ensemble-mean warm bias. The relatively rapid increase of the warm bias from November through February is reminiscent of the rapid seasonal retreat of sea ice, which is explained by heat from ocean upwelling, in addition to atmospheric forcing (e.g., Gordon 1981). The gradual decline of the warm bias from March through September broadly parallels the seasonality of the mixed layer depth within and to the north of the ACC (e.g., Sallée et al. 2010). The mixed layer slowly deepens during autumn and winter as buoyancy forcing decreases. It rapidly shoals during the spring, and is shallowest during December and January. Nonetheless, the peak of the oceanic warm bias in February is consistent with a lagged thermal response to anomalous shortwave forcing in midsummer, not with the timing of the shallowest mixed layer.

The SAT bias on land is not obviously related to biases in the radiation budget. In all months but December, $\mathrm{LW}_{\text {net }}$ and $R_{\text {net }}$ are negatively biased and $\mathrm{SW}_{\text {net }}$ is very close to CERES-EBAF. In December, $\mathrm{SW}_{\text {net }}$ is negatively biased, $\mathrm{LW}_{\text {net }}$ is positively biased, and $R_{\text {net }}$ is close to the observations.

The opposite shortwave radiation biases in summer on the AIS and Southern Ocean suggest that different aspects of the models may be contributing to these biases. From the top-of-atmosphere perspective, the collective impacts of properties such as clouds and 
surface albedo on the radiation budget have a fingerprint in the ASR. In the zonal mean, insolation peaks over the pole during summer (Fig. 5a), but the ASR peaks in the subtropics (Fig. 5b), due in part to the maximum in SWCF in the SH midlatitudes (Fig. 5c), and to the high surface albedo of the AIS and seasonal sea ice zone (Fig. 5d). The ASR is sensitive to the sharp latitudinal contrasts in albedo and SWCF, and below we will explore how these surface properties and processes relate to the ensemble mean biases and intermodel spread in the simulated surface climate.

\section{Evaluation of summer surface climate in individual models}

Having highlighted the prominent ensemble-mean SAT bias in summer over the ocean and the large intermodel range in summer SAT on land, we now turn to the characteristics of the SAT and radiation simulations in individual models, focusing on DJF. The observed SAT field in DJF is characterized by extreme cold on the plateau of East Antarctica, relative warmth around the coast of Antarctica, and increasing SAT over the ocean toward the north (Fig. 6a). This general spatial pattern is replicated by the ensemble mean (Fig. 6b), which has biases of $0.7^{\circ}$ and $0.9^{\circ} \mathrm{C}$ over the land and ocean, respectively. The ensemble mean hides a substantial intermodel range over both land and ocean. On land, the mean SAT varies from $7.6^{\circ} \mathrm{C}$ higher than UDEL (BNU-ESM; Fig. 6c) to $5.0^{\circ} \mathrm{C}$ less than UDEL (CanESM2; Fig. 6d). Over the ocean, the warmest and coldest models (with respect to ERAI) are the GISS-E2-H (Fig. 6d) and IPSL-CM5A-LR (Fig. 6e), respectively. Figures 7, 8, and 9 show the corresponding ASR, SWCF, and surface albedo fields from these same models. The SAT, SWCF, ASR, and surface albedo fields for all 26 models are shown in the supplemental material.

On land, the warmest model, BNU-ESM, has $13 \mathrm{~W} \mathrm{~m}^{-2}$ more ASR than CERES-EBAF, while the coldest model, CanESM2, has $11.3 \mathrm{~W} \mathrm{~m}^{-2}$ less ASR than CERES-EBAF (Figs. 7c,d). This range cannot be explained by SWCF, as BNU-ESM actually has stronger (more negative) SWCF than does CanESM2 (Figs. 8c,d), and the range between these models in SWCF is roughly one-third the range in ASR. The average surface albedo of the AIS in these models (Figs. 9c,d) differs by about 0.072 , which would explain a difference in ASR of about $24 \mathrm{~W} \mathrm{~m}^{-2}$ if the downward shortwave radiation is similar to the ensemble mean value of $336 \mathrm{~W} \mathrm{~m}^{-2}$ (Table 3 ).

Over the ocean, comparison of the GISS-E2-H and the IPSL-CM5A-LR models exemplifies the large
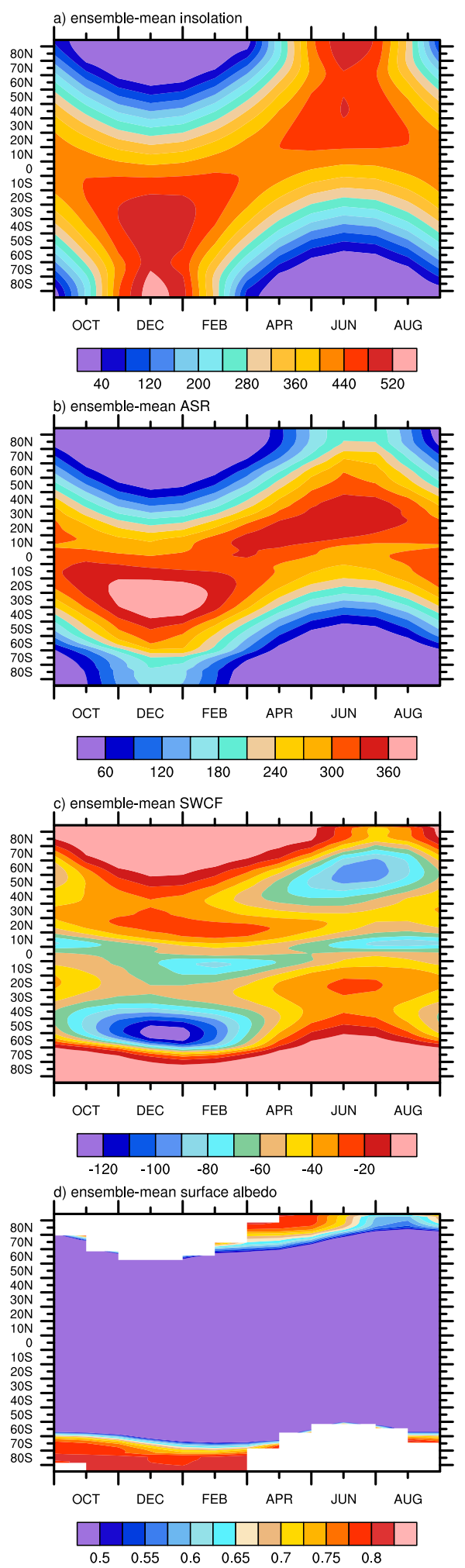

FIG. 5. Monthly, ensemble-mean, zonal-mean simulations of (a) insolation $\left(\mathrm{W} \mathrm{m}^{-2}\right), \operatorname{ASR}\left(\mathrm{W} \mathrm{m}^{-2}\right),(\mathrm{c}) \operatorname{SWCF}\left(\mathrm{W} \mathrm{m}^{-2}\right)$, and (d) clear-sky surface albedo. 
a) ERAI/UDEL

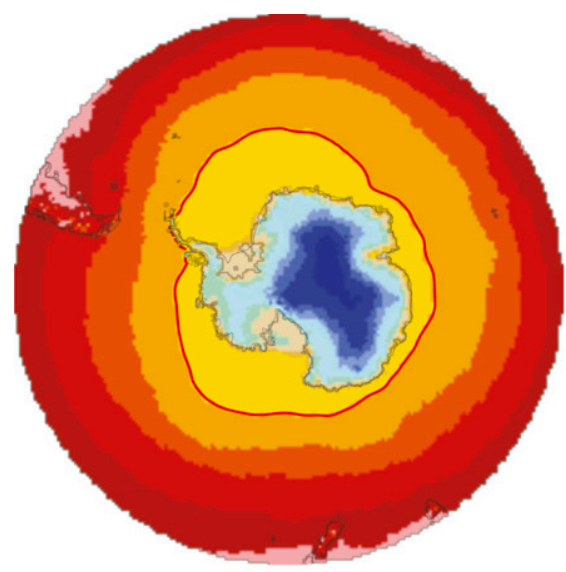

c) BNU-ESM 7.6( 1.0)

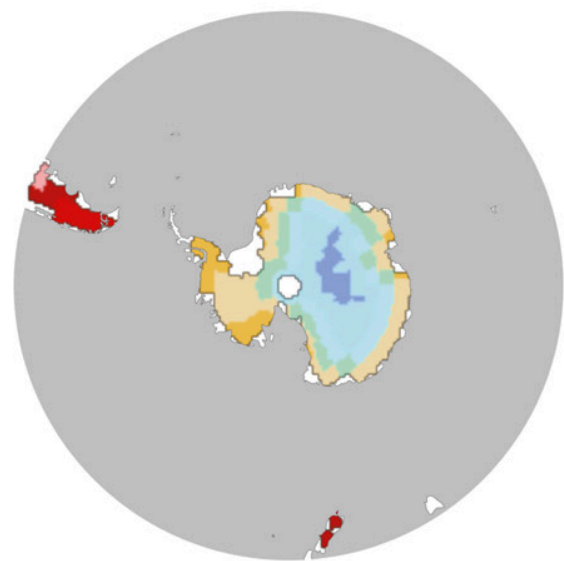

e) GISS-E2-H 1.5( 4.0)

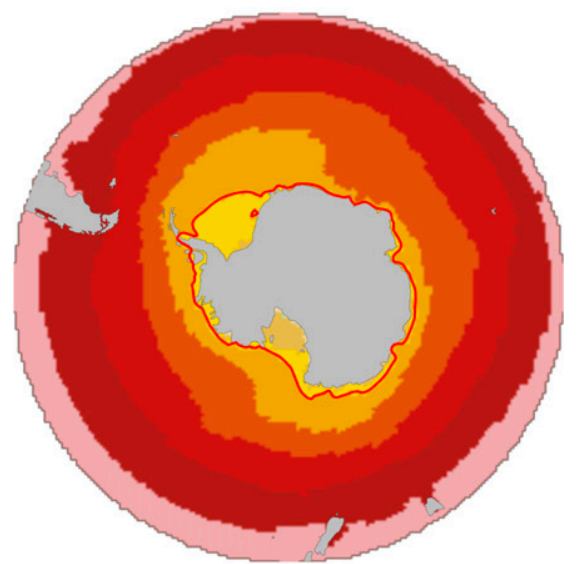

b) ENS $0.7(0.9)$
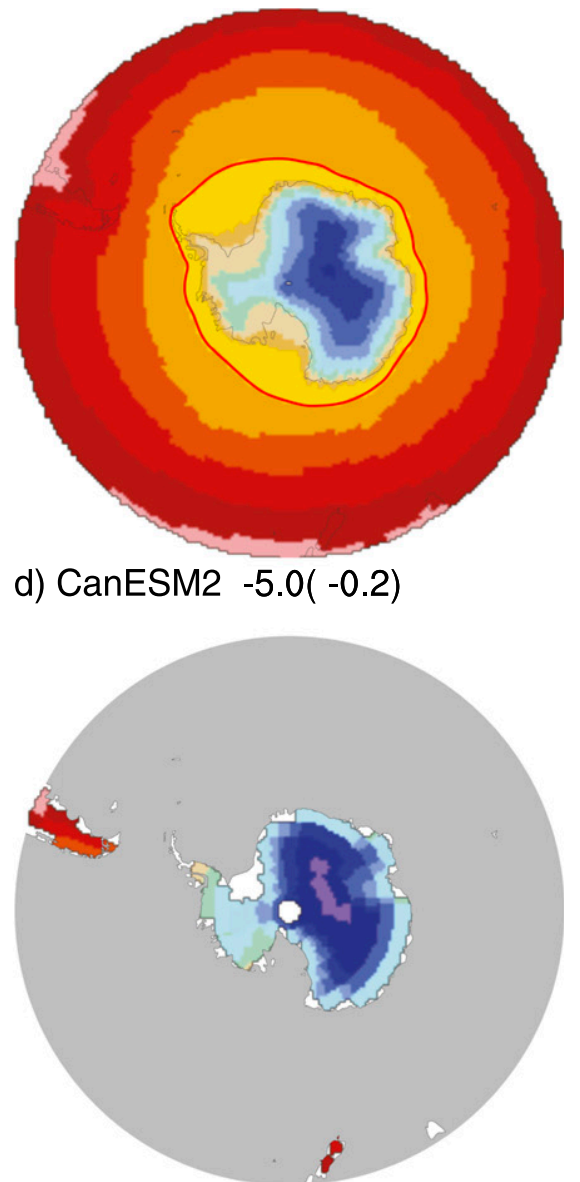

f) IPSL-CM5A-LR -1.3(-1.9)

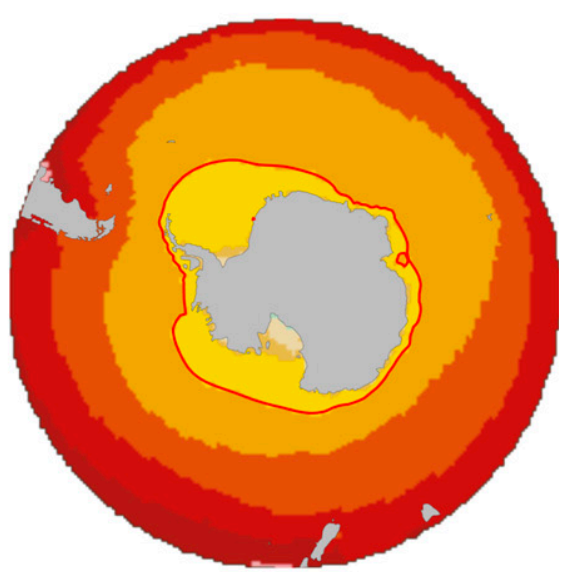

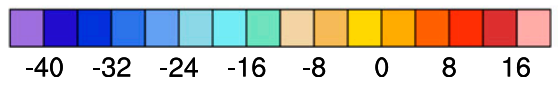

FIG. 6. DJF SAT climatology $\left({ }^{\circ} \mathrm{C}\right)$ for (a) ERAI over the ocean and UDEL over the land, (b) the 26-model ensemble mean, (c) the warmest of the 26 models over land, (d) the coldest of the 26 models over land, (e) the warmest of the 26 models over ocean, and (f) the coldest of the 26 models over ocean. The red lines in (a),(b),(e),(f) correspond with the $0^{\circ} \mathrm{C}$ summer isotherm. The numbers to the right of the model names give the biases averaged over the land and ocean (in parentheses) domains. 
a) CERES-EBAF

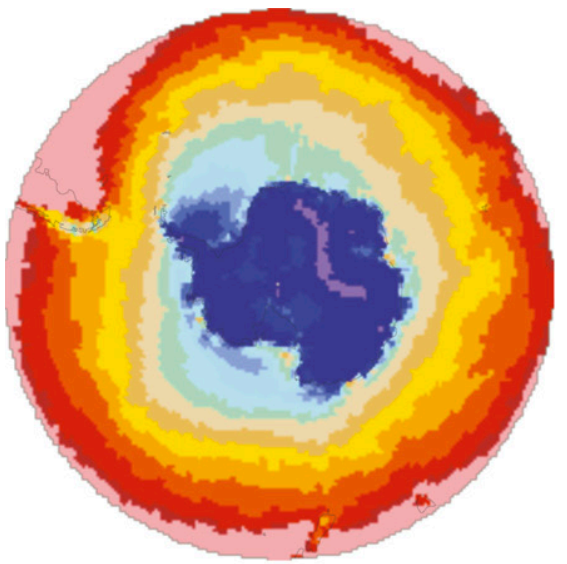

c) BNU-ESM 13.4( 6.4)

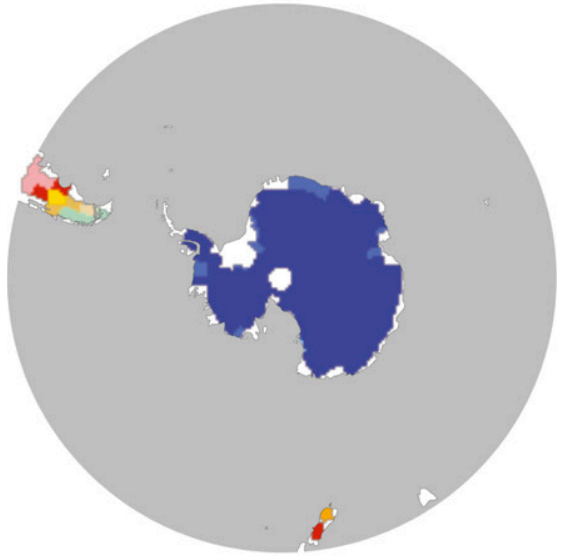

e) GISS-E2-H 1.4( 36.9)

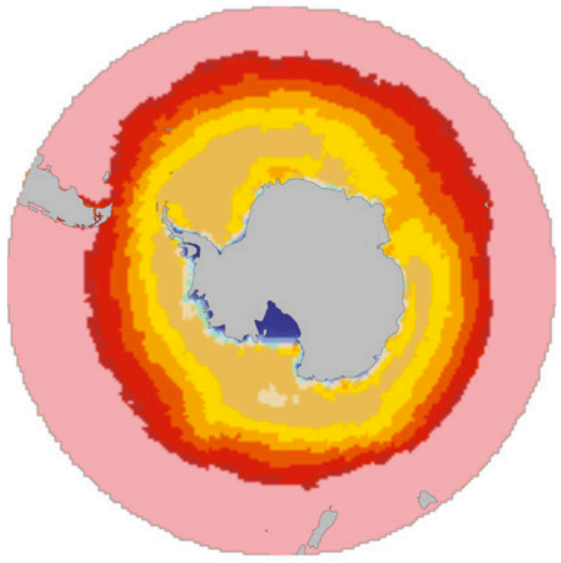

b) ENS 1.8( 7.9$)$

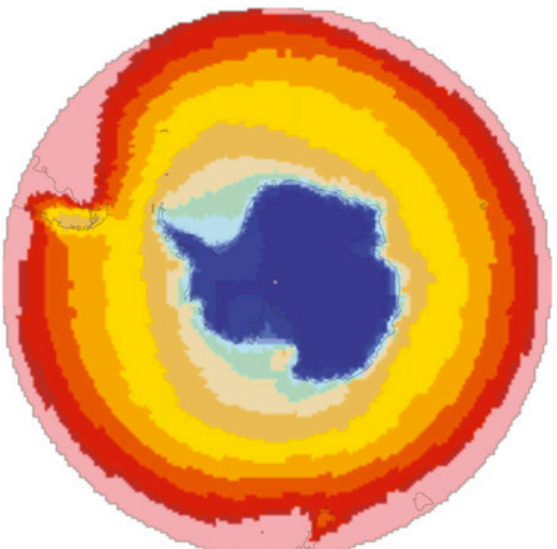

d) CanESM2 -11.3( -2.0)

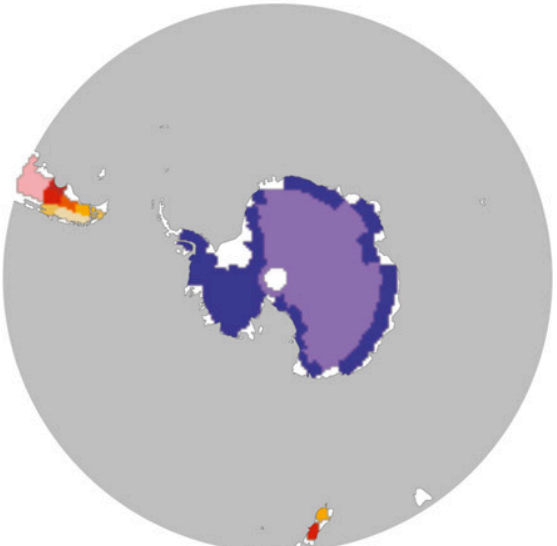

f) IPSL-CM5A-LR 4.4(-34.3)

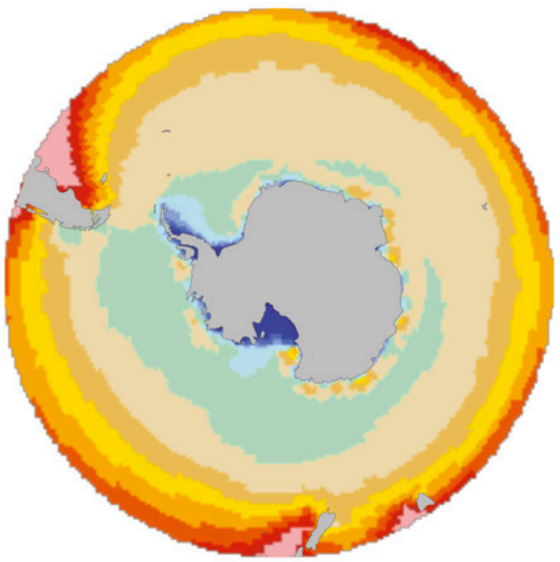

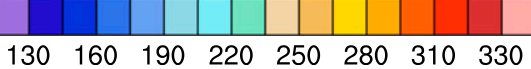

FIG. 7. DJF ASR climatology $\left(\mathrm{W} \mathrm{m}^{-2}\right.$ ) for (a) CERES-EBAF, (b) the 26-model ensemble mean, (c) the warmest and (d) the coldest of the 26 models over land, and (e) the warmest and (f) the coldest of the 26 models over ocean. The numbers to the right of the model names give the biases averaged over the land and ocean (in parentheses) domains. 
a) CERES-EBAF
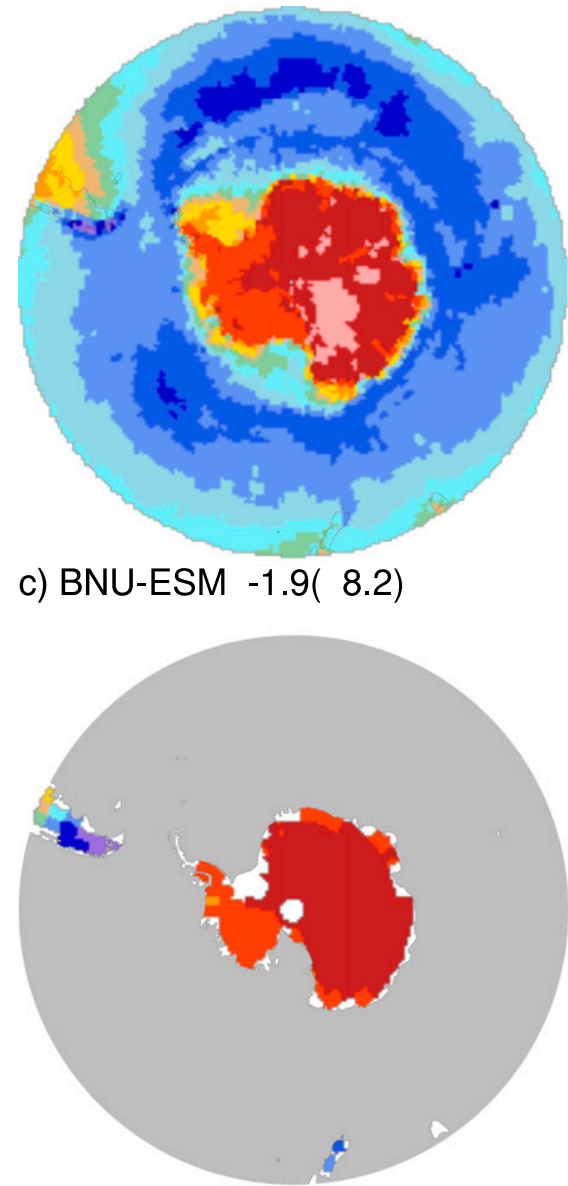

e) GISS-E2-H 5.0( 39.9)

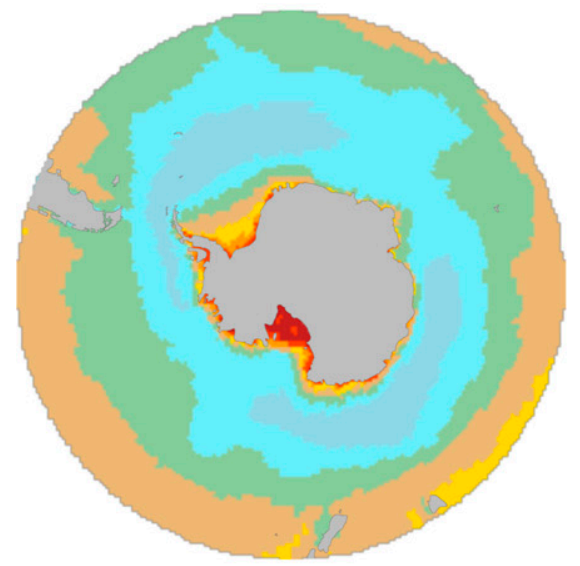

b) ENS 2.7( 7.7)
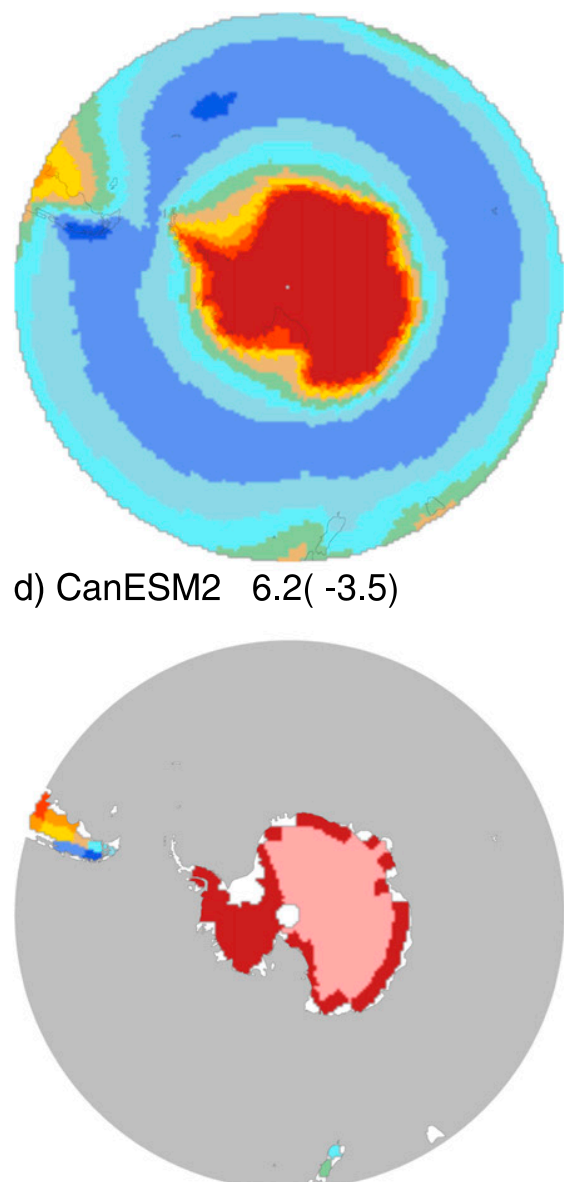

f) IPSL-CM5A-LR -0.4(-37.6)

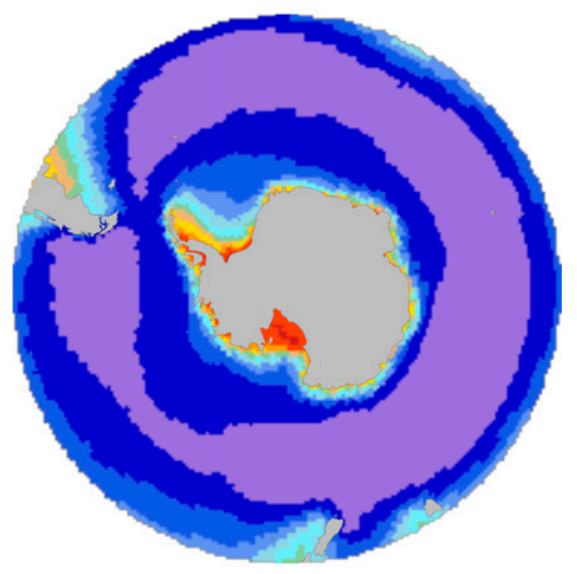

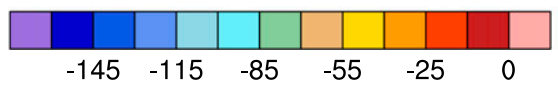

FIG. 8. As in Fig. 7, but for DJF SWCF climatology $\left(\mathrm{W} \mathrm{m}^{-2}\right)$. 
a) CERES-EBAF

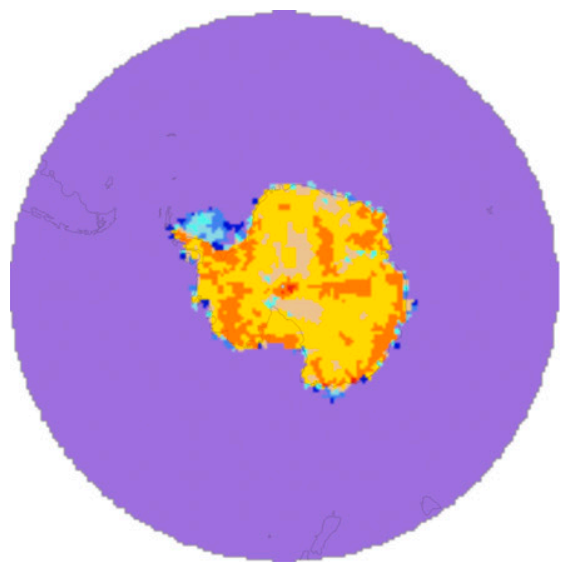

c) BNU-ESM -1.0( 1.0)

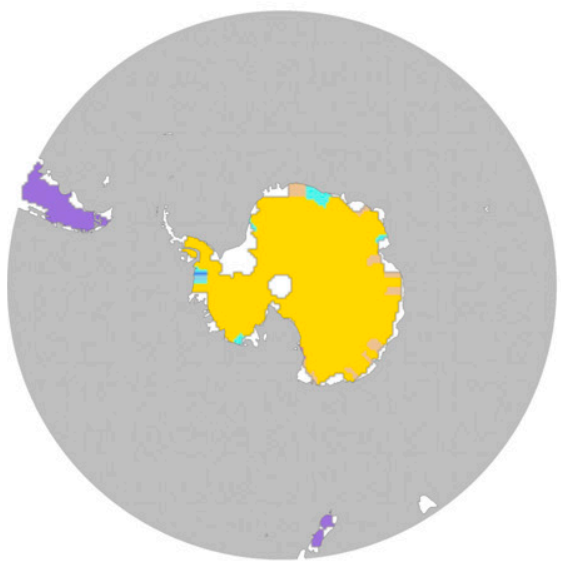

e) GISS-E2-H 3.1(-0.2)

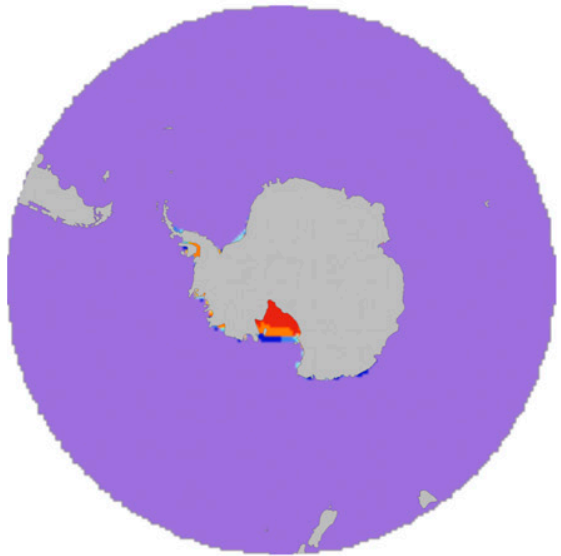

b) ENS 2.1( 0.4)

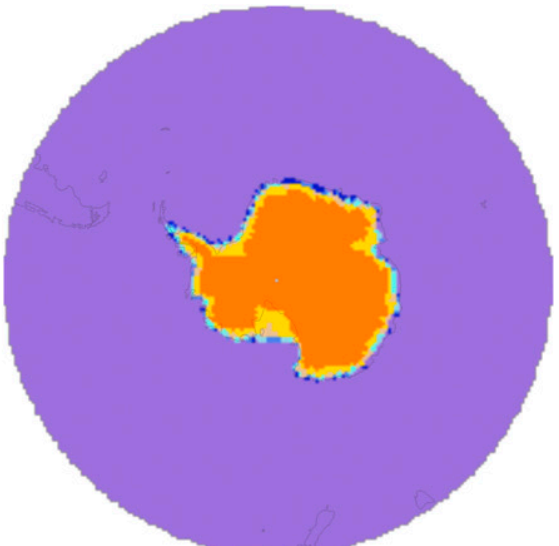

d) CanESM2 6.2( 0.6)

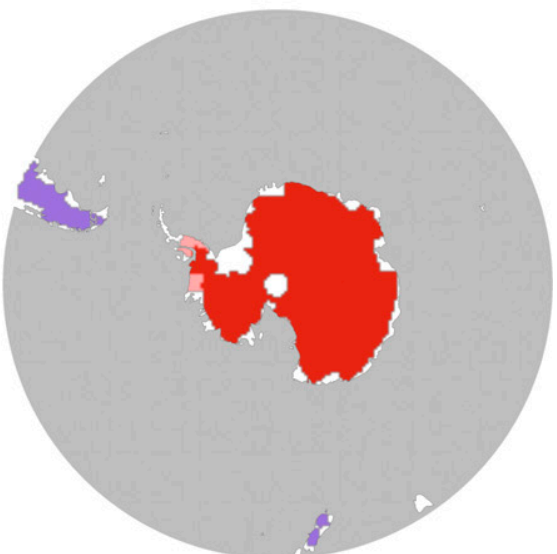

f) IPSL-CM5A-LR $0.3(0.7)$

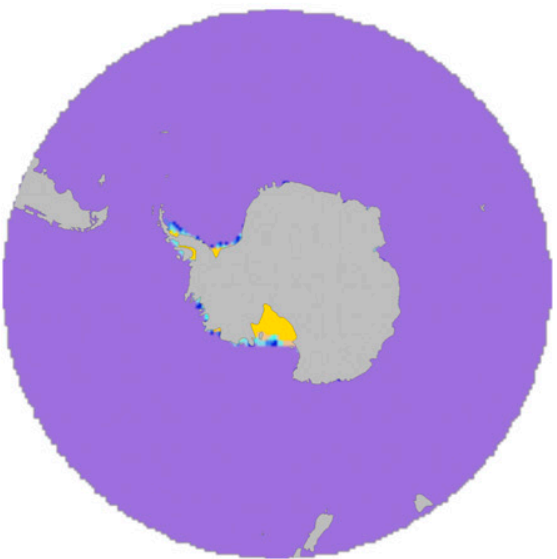

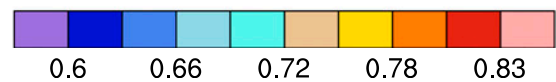

FIG. 9. DJF surface albedo climatology for (a) CERES-EBAF, (b) the 26-model ensemble mean, (c) the warmest of the 26 models over land, (d) the coldest of the 26 models over land, (e) the warmest of the 26 models over ocean, and (f) the coldest of the 26 models over ocean. Units are dimensionless. The numbers given to the right of the model names are the biases times 100 . For example, the ensemble mean is biased by 0.021 relative to CERES-EBAF over the AIS. 
TABLE 3. Ensemble-mean (ENS) and observational values of the major terms in the radiation budgets (W $\mathrm{m}^{-2}$; except albedo) for the AIS and the Southern Ocean. Note that the albedo values given here are for all-sky conditions.

\begin{tabular}{|c|c|c|c|c|c|c|}
\hline & EBAF land & ENS land & Land bias & EBAF ocean & ENS ocean & Ocean bias \\
\hline \multicolumn{7}{|l|}{ DJF surface } \\
\hline $\mathrm{SW}_{u}$ & 263.2 & 264.6 & 1.4 & 11.8 & 13.1 & 1.2 \\
\hline $\mathrm{SW}_{d}$ & 337.0 & 336.3 & -0.7 & 207.7 & 218.1 & 10.4 \\
\hline $\mathrm{SW}_{\text {net }}$ & 73.8 & 71.7 & -2.1 & 195.9 & 205.1 & 9.2 \\
\hline Albedo & 0.78 & 0.79 & 0.01 & 0.06 & 0.06 & 0.00 \\
\hline $\mathrm{LW}_{u}$ & 227.7 & 224.5 & -3.2 & 359.0 & 362.4 & 3.5 \\
\hline $\mathrm{LW}_{d}$ & 162.4 & 157.7 & -4.7 & 321.6 & 320.2 & -1.4 \\
\hline $\mathrm{LW}_{\text {net }}$ & -65.3 & -66.9 & -1.5 & -37.4 & -42.2 & -4.8 \\
\hline$R_{\text {net }}$ & 8.5 & 4.9 & -3.6 & 158.5 & 162.9 & 4.4 \\
\hline CRE-LWs & 29.3 & 22.4 & -6.9 & 52.2 & 45.7 & -6.5 \\
\hline \multicolumn{7}{|l|}{ DJF TOA } \\
\hline $\mathrm{SW}_{d}$ & 435.4 & 441.0 & 5.6 & 464.6 & 467.8 & 3.2 \\
\hline $\mathrm{SW}_{u}$ & 295.1 & 298.9 & 3.8 & 168.6 & 163.8 & -4.7 \\
\hline ASR & 140.3 & 142.1 & 1.8 & 296.1 & 304.0 & 7.9 \\
\hline Albedo & 0.68 & 0.68 & 0.00 & 0.36 & 0.35 & -0.01 \\
\hline SWCF & -6.3 & -3.5 & 2.8 & -118.1 & -110.4 & 7.7 \\
\hline \multicolumn{7}{|l|}{ JJA surface } \\
\hline $\mathrm{SW}_{u}$ & 1.6 & 1.4 & -0.1 & 3.9 & 4.6 & 0.8 \\
\hline $\mathrm{SW}_{d}$ & 2.1 & 1.8 & -0.3 & 44.4 & 43.9 & -0.5 \\
\hline $\mathrm{SW}_{\text {net }}$ & 0.6 & 0.4 & -0.2 & 40.5 & 39.2 & -1.2 \\
\hline Albedo & 0.74 & 0.81 & 0.07 & 0.09 & 0.11 & 0.02 \\
\hline $\mathrm{LW}_{u}$ & 153.6 & 150.9 & -2.8 & 346.2 & 346.7 & 0.5 \\
\hline $\mathrm{LW}_{d}$ & 137.4 & 112.2 & -25.2 & 302.9 & 297.1 & -5.9 \\
\hline $\mathrm{LW}_{\text {net }}$ & -16.2 & -38.6 & -22.4 & -43.3 & -49.7 & -6.4 \\
\hline$R_{\text {net }}$ & -15.7 & -38.3 & -22.6 & -2.8 & -10.4 & -7.6 \\
\hline CRE-LWs & 40.1 & 19.1 & -21.0 & 53.6 & 47.6 & -5.9 \\
\hline
\end{tabular}

intermodel range in ASR, a difference of about $71 \mathrm{~W} \mathrm{~m}^{-2}$ (Figs. 7e,f). This difference can be more than accounted for by the SWCF, which is $78 \mathrm{~W} \mathrm{~m}^{-2}$ stronger in IPSL-CM5A-LR than in GISS-E2-H (Figs. 8e,f). The majority of the 26 models have more ASR and weaker SWCF than observed (Figs. S4 and S5 in the supplemental material), and this is reflected in the ensemble means (Figs. $7 \mathrm{~b}$ and $8 \mathrm{~b}$ ). The ensemblemean biases in ASR and SWCF are both about $8 \mathrm{~W} \mathrm{~m}^{-2}$ (Table 3).

Do these qualitative relationships among the ASR, SWCF, and surface albedo between the extreme models apply more generally across models, and further, do any of these variables help to explain the model spread in SAT? To address this question, the models spreads in SAT, insolation, ASR, surface albedo, and SWCF are compared in Fig. 10 for both the ocean and land domains. In addition, correlations among these variables are given in Table 4. ASR helps to explain the spread in SAT in both domains. The correlations between SAT and ASR are $r=0.78$ and $r=0.70$ for the ocean and ice sheet, respectively (Table 4). The intermodel spreads of SAT over the Southern Ocean and AIS are not significantly correlated $(r=0.31)$. The model spread in ASR over the ocean is strongly correlated with the model spread in SWCF $(r=-0.98)$ and the model spread in ASR over the AIS is strongly correlated with the model spread in surface albedo $(r=-0.90)$. Figures 11a and 11b contain scatterplots of these regressions, showing that the relationships are quite linear. In the map view, the model spread in surface albedo over the AIS exhibits a strong correlation with the spread in ASR over the AIS (Fig. 11c), while the model spread in SWCF over the ocean exhibits strong correlation with the model spread in ASR over the ocean (Fig. 11d). The standard deviation of the model spreads, indicated in Fig. 10, further supports the hypothesis that the spread in surface albedo is the dominant cause of the spread in ASR over the ice sheet, and the spread in SWCF is the dominant cause of the spread in ASR over the ocean. Over the ocean, the standard deviation in SWCF $\left(19 \mathrm{~W} \mathrm{~m}^{-2}\right)$ is close to the standard deviation of the ASR $\left(18 \mathrm{~W} \mathrm{~m}^{-2}\right)$, while the insolation has a small standard deviation of $1.11 \mathrm{~W} \mathrm{~m}^{-2}$. On land, the standard deviation of the surface albedo is 0.024 , which is large enough to explain the standard deviation of $7.5 \mathrm{~W} \mathrm{~m}^{-2}$ in ASR, considering that the ensemble mean $\mathrm{SW}_{d}$ at the surface is $336 \mathrm{~W} \mathrm{~m}^{-2}$ (Table 3). Conversely, SWCF does not explain the model spread in ASR over the ice sheet, and albedo does not explain the spread in ASR over the ocean. Also, while the top-of-atmosphere insolation is a 

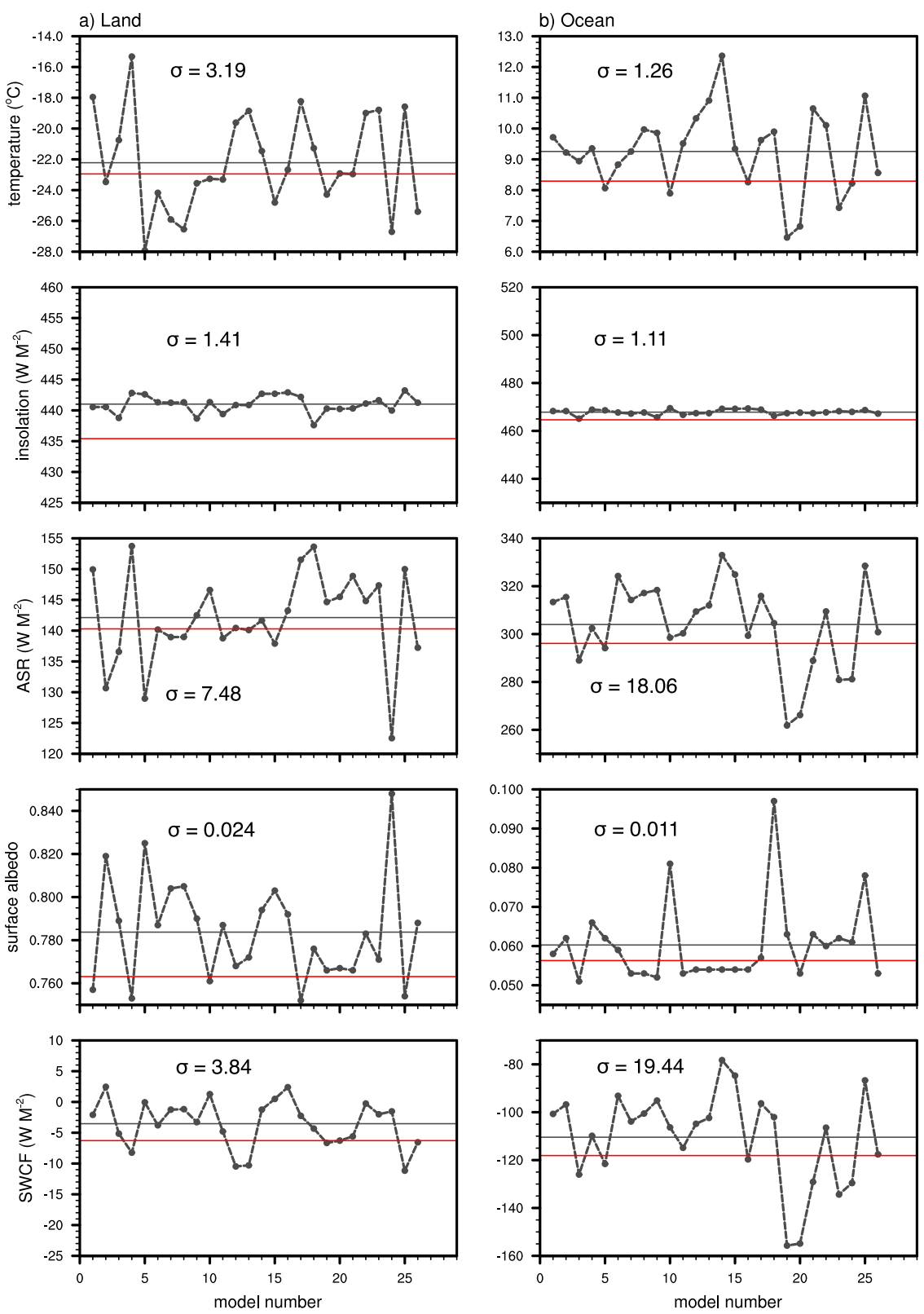

FIG. 10. The DJF SAT, insolation, ASR, surface albedo, and SWCF in 26 models for (a) land and (b) ocean domains. Model numbers correspond with Table 1. The ensemble-mean values are indicated by the horizontal gray lines. The observed values (from UDEL for SAT over land, ERAI for SAT over ocean, and CERES-EBAF for all other quantities) are given as horizontal red lines. The standard deviation $\sigma$ of the model spread is indicated in each panel.

major term in the mean ASR by definition, it does not vary sufficiently among models to explain the substantial model spread in ASR and the surface climate.

Since the ASR is relevant to aspects of the surface climate over both the AIS and Southern Ocean, we use it as a diagnostic to summarize model performance. The ensemble mean has excessive ASR in both domains (Fig. 7). Figure 12 is a Taylor diagram (Taylor 2001) of
ASR in CMIP5 models over $40^{\circ}-90^{\circ} \mathrm{S}$, using CERESEBAF data as the benchmark. The Taylor diagram includes information on the spatial pattern correlation, RMSE, and temporal standard deviation of a model field compared with observations. Pattern correlations range from about 0.9 to 0.99 . The RMSE is proportional to the straight-line distance from the model to the point marked EBAF. By the pattern correlation and RMSE, 
TABLE 4. Correlations of the intermodel spread of summer (DJF) SAT and ASR integrated over the land and ocean with various quantities in their respective domains. Boldface numbers indicate statistical significance at $95 \%$ or above.

\begin{tabular}{lrccr}
\hline & SAT land & ASR land & ASR ocean & SAT ocean \\
\hline TOA & & & & \\
ASR & $\mathbf{0 . 7 0}$ & - & - & $\mathbf{0 . 7 8}$ \\
SWCF & -0.42 & -0.31 & $\mathbf{- 0 . 9 8}$ & $-\mathbf{0 . 7 7}$ \\
Surface & & & & \\
Albedo & $\mathbf{- 0 . 7 4}$ & $\mathbf{- 0 . 9 0}$ & -0.03 & -0.03 \\
SW $_{\text {net }}$ & 0.48 & $\mathbf{0 . 8 2}$ & $\mathbf{0 . 9 9}$ & $\mathbf{0 . 7 9}$ \\
LW $_{\text {net }}$ & 0.01 & $\mathbf{- 0 . 5 1}$ & $\mathbf{- 0 . 8 0}$ & $\mathbf{- 0 . 6 7}$ \\
$R_{\text {net }}$ & 0.63 & 0.35 & $\mathbf{0 . 9 6}$ & $\mathbf{0 . 7 5}$ \\
HF $_{\text {net }}$ & $\mathbf{- 0 . 7 8}$ & $-\mathbf{0 . 4 8}$ & $\mathbf{- 0 . 5 8}$ & $\mathbf{0 . 6 2}$ \\
SEF $_{\text {net }}$ & -0.41 & -0.34 & $\mathbf{0 . 9 1}$ & $\mathbf{0 . 6 2}$ \\
\hline
\end{tabular}

NorESM1-M ranks highest and GFDL-ESM2G ranks the lowest. In second place is CESM1(CAM5) with a $2^{\circ}$ finite volume grid [CESM1(CAM5, FV2)]. It is notable that NorESM1-M and CESM1(CAM5, FV2) share a common predecessor atmospheric model, CAM4 (used by CCSM4). Two separate teams made efforts to improve aspects of the cloud simulations in CAM4: Bentsen et al. (2013) describe the development related to Nor-ESM1-M using CAM4-Oslo and Kay et al. (2012) summarize improvements in CAM5 over CAM4. These efforts have led to progress in climate simulations over the Southern Ocean but, as revealed by the energy budget analysis below, several additional processes need attention from developers.

\section{Surface energy fluxes}

\section{a. Surface energy flux in summer}

The major terms contributing to $\mathrm{SEF}_{\text {net }}$ are presented in Fig. 13. In summer, the land surface absorbs a substantial amount of shortwave radiation, as indicated by the positive $\mathrm{SW}_{\text {net }}$ in all models (Fig. 13a). Consistent with the stronger emission of a warmer snow surface, $\mathrm{LW}_{\text {net }}$ is generally more negative in the warmer models. In 20 of 26 models, $\mathrm{SW}_{\text {net }}$ exceeds $\mathrm{LW}_{\text {net }}$, resulting in a small positive $R_{\text {net }}$ with an intermodel range of about $20 \mathrm{~W} \mathrm{~m}^{-2}$. Note that $R_{\text {net }}$ is opposed by $\mathrm{HF}_{\text {net }}$, such that the models with $R_{\text {net }}$ greater than the ensemble mean of $5 \mathrm{~W} \mathrm{~m}^{-2}$ have negative (upward) heat fluxes, associated with convection (reflected in the sensible heat flux) or sublimation (reflected in the latent heat flux). Models with a deficit in $R_{\text {net }}$ relative to the ensemble mean exhibit heat fluxes directed toward the surface, associated with sensible heat transport or the deposition of snow or frost. The variation in the heat fluxes plays a significant role in the SAT: the intermodel spreads of SAT and $\mathrm{HF}_{\text {net }}$ are correlated at $r=-0.78$ (Table 4). Owing to the number of processes involved in the heat fluxes, there is not an exact offsetting between $R_{\text {net }}$ and $\mathrm{HF}_{\text {net }}$, resulting in a wide intermodel range of $\mathrm{SEF}_{\text {net. }}$. In all models, $\mathrm{SEF}_{\text {net }}$ is positive, directed downward into the snowpack. The sign of $\mathrm{SEF}_{\text {net }}$ agrees with limited observations from Antarctica (e.g., Warren 1996; van den Broeke et al. 2005), but the magnitude of $\mathrm{SEF}_{\text {net }}$ in several models exceeds the largest reported values of approximately $6 \mathrm{~W} \mathrm{~m}^{-2}$ (e.g., Warren 1996). To be consistent with observations, more of the positive $R_{\text {net }}$ should be balanced by a stronger upward (negative) $\mathrm{HF}_{\text {net }}$, in favor of the convection and sublimation processes observed across the AIS during summer (van den Broeke et al. 2005). On the polar plateau in summer, shallow convection and the development of a shallow mixed layer above the surface can occur as a response to daytime heating (e.g., van den Broeke et al. 2005).

Over the ocean, there is a tight correlation between the model spreads in $\mathrm{SW}_{\text {net }}, R_{\text {net }}$, and $\mathrm{SEF}_{\text {net }}$ (Fig. 13b and Table 4). It is found that $\mathrm{SW}_{\text {net }}$ covaries strongly with the ASR and SWCF, with an intermodel range of about $80 \mathrm{~W} \mathrm{~m}^{-2}$, far exceeding the range of $\mathrm{LW}_{\text {net }}$. The intermodel spread in $R_{\text {net }}$ is dominated by the spread in $\mathrm{SW}_{\text {net }}(r=0.96)$. Also, $\mathrm{HF}_{\text {net }}$ is directed upward, out of the ocean in all models, with a tendency for warmer models with larger $R_{\text {net }}$ to have a stronger upward heat flux. Finally, $R_{\text {net }}$ is much larger than $\mathrm{HF}_{\text {net }}$ in the summer (Figs. $3 \mathrm{~b}$ and 13b), so the model spread in $\mathrm{SEF}_{\text {net }}$ is driven by the spread in $R_{\text {net }}$.

\section{b. Surface energy flux in winter}

In winter, the surface energy budget over the AIS is much different than during the brief summer season (Fig. 14a). The value of $R_{\text {net }}$ is negative in all models, and is mostly balanced by the large $\mathrm{HF}_{\text {net }}$ directed from the atmosphere toward the surface. The intermodel spread in SAT is significantly correlated with both $\mathrm{LW}_{\text {net }}(r=-0.60)$ and $\mathrm{HF}_{\text {net }}(r=0.60)$, which in turn are strongly correlated with each other $(r=-0.95)$. The spread in $\mathrm{LW}_{\text {net }}$ arises mainly from the spread in $\mathrm{LW}_{u}$. As an illustration, consider the coldest and warmest models, the CSIRO Mk3.0 and the GISS-E2-H, respectively. The mean JJA SAT is $-50.3^{\circ} \mathrm{C}$ in CSIRO $\mathrm{Mk} 3.0$ and $-40.5^{\circ} \mathrm{C}$ in GISS-E2-H. Solving the StefanBoltzman law for these temperatures, assuming blackbody surface emission and that the SAT and surface (skin) temperatures are similar, yields a difference of approximately $26 \mathrm{~W} \mathrm{~m}^{-2}$ in the radiation emitted by the two surfaces, close to the actual $\mathrm{LW}_{u}$ difference of approximately $29 \mathrm{~W} \mathrm{~m}^{-2}$. The $\mathrm{LW}_{\text {net }}$ difference between these models is $26 \mathrm{~W} \mathrm{~m}^{-2}$. The smaller $\mathrm{LW}_{\text {net }}$ difference is explained by $\mathrm{LW}_{d}$, which is $2 \mathrm{~W} \mathrm{~m}^{-2}$ greater in GISSE2-H than in CSIRO Mk3.0. The $R_{\text {net }}$ deficit of the 
a) land ASR vs. albedo

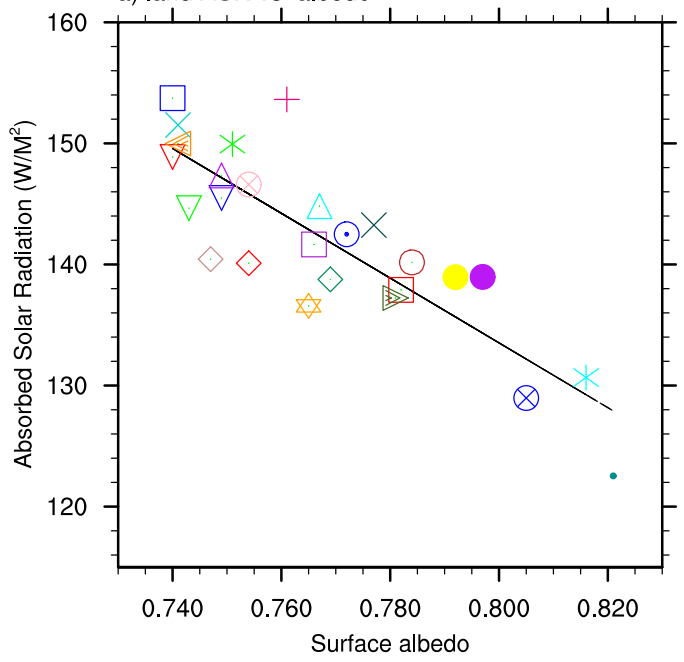

c) ASR vs. ice sheet albedo
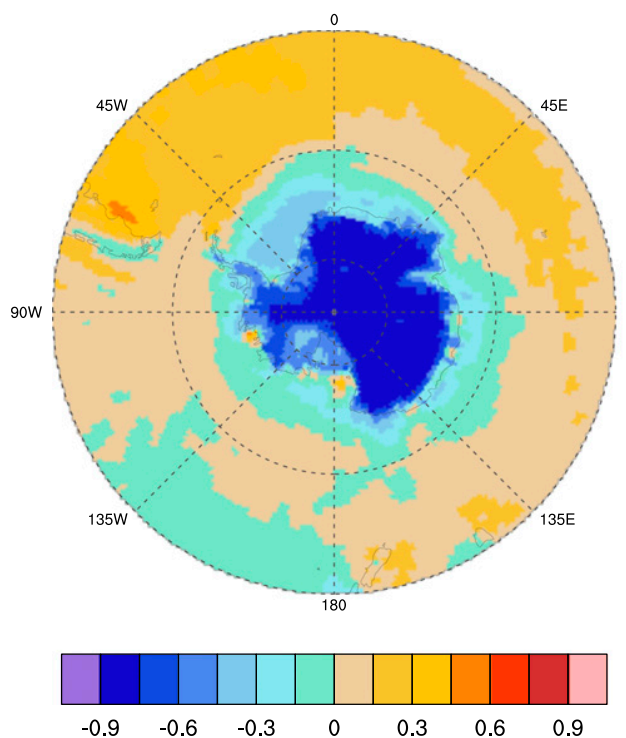

b) ocean ASR vs. SWCF

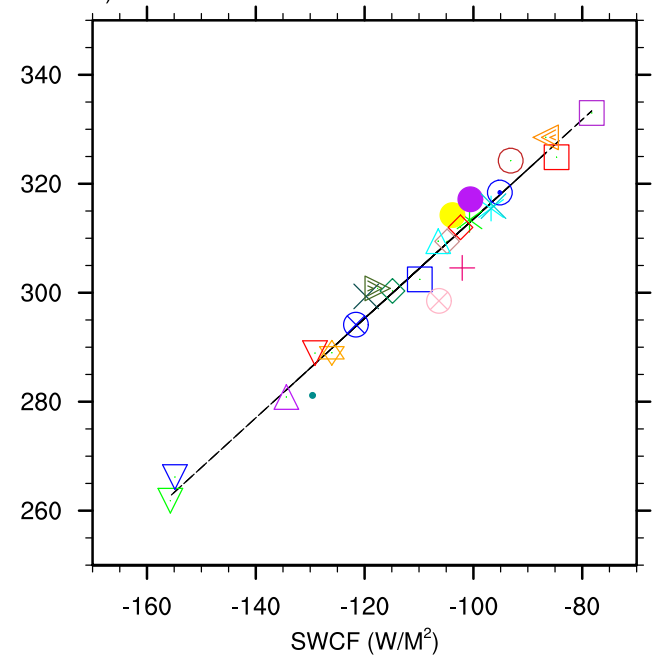

d) ASR vs. ocean SWCF
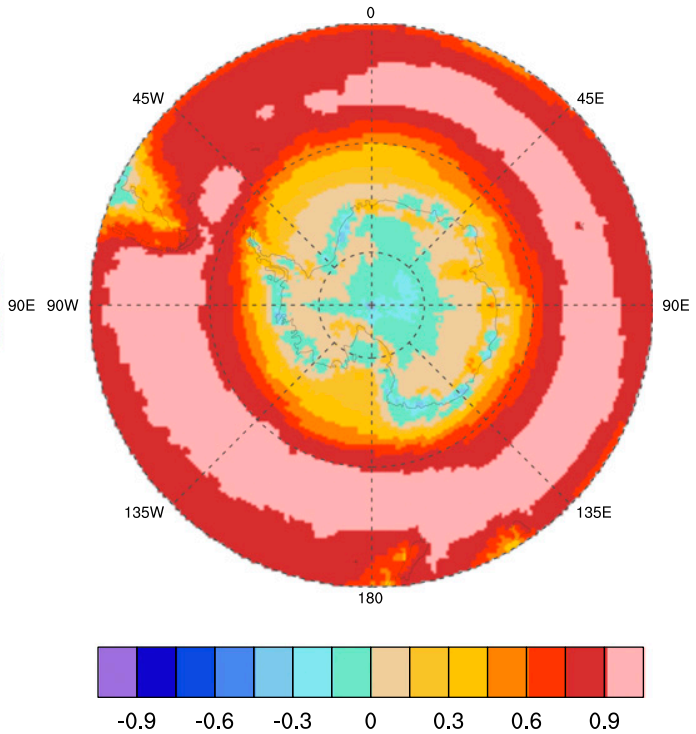

FIG. 11. Regression of ASR integrated (a) over the AIS upon AIS surface albedo and (b) over $40^{\circ}-60^{\circ} \mathrm{S}$ upon SWCF over the same region. Symbols correspond with individual models (see key given in Fig. 12). Also shown is correlation of the model spread in ASR at each grid point with (c) the model spread in surface albedo over the AIS and (d) the model spread in SWCF integrated over ocean grid points $40^{\circ}-60^{\circ} \mathrm{S}$.

GISS-E2-H model of $-51 \mathrm{Wm}^{-2}$ is countered by a turbulent heat flux of $42 \mathrm{~W} \mathrm{~m}^{-2}$ and a subsurface heat flux of $9 \mathrm{~W} \mathrm{~m}^{-2}$, both of which act to warm the surface.

Of particular concern is the strong bias in $R_{\text {net }}$ with respect to observations: the ensemble-mean $R_{\text {net }}$ is $22.6 \mathrm{~W} \mathrm{~m}^{-2}$ less than CERES-EBAF (Fig. 15b). The ensemble mean is representative of most individual models (Fig. S7 in the supplemental material) in showing a much stronger radiation deficit over the polar plateau than CERES-EBAF (Fig. 15a). No models reproduce the $R_{\text {net }}$ values from -10 to $-15 \mathrm{~W} \mathrm{~m}^{-2}$ that are typical for the East Antarctic plateau in winter. While the CERES-EBAF data have considerable uncertainty, the relatively modest radiation deficits in the Antarctic interior shown in Fig. 15a are consistent with in situ measurements (van den Broeke et al. 2005; Cullather and Bosilovich 2012). The ensemble mean $R_{\text {net }}$ value of $-38 \mathrm{~W} \mathrm{~m}^{-2}$ (Table 3 ) is not uncommon in the Antarctic winter but it is characteristic of regions of steep topography and strong winds during clear-sky 


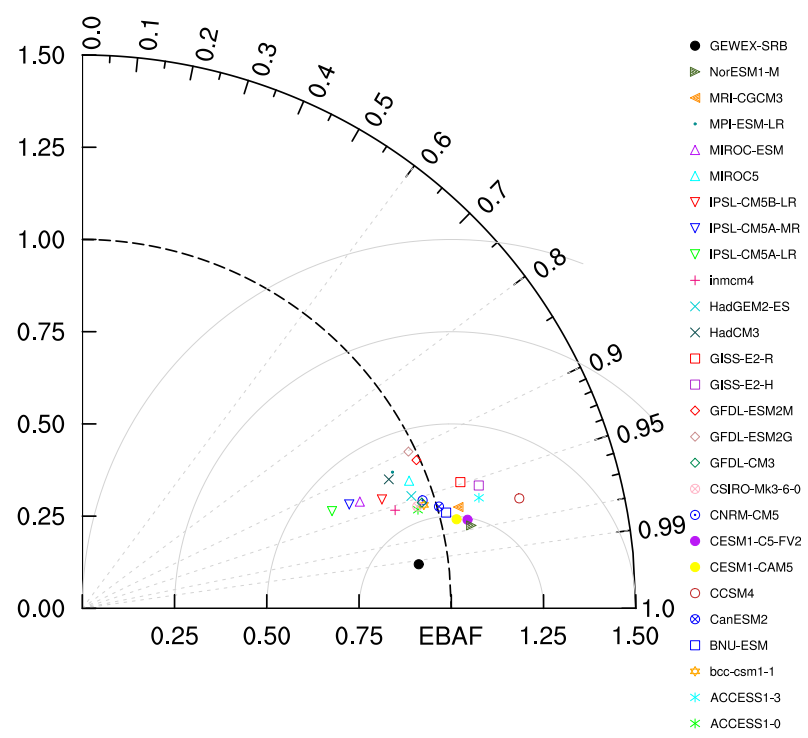

FIG. 12. Taylor diagram of the ASR in DJF for 26 models in reference to CERES-EBAF, over the domain $40^{\circ}-90^{\circ} \mathrm{S}$.

conditions, not the interior or Antarctica as a whole (van den Broeke et al. 2005). A closer look at the individual terms contributing to $R_{\text {net }}$ reveals that $\mathrm{LW}_{d}$ accounts for the largest share $\left(-25.2 \mathrm{~W} \mathrm{~m}^{-2}\right)$ of the $R_{\text {net }}$ bias in the ensemble mean; $\mathrm{LW}_{u}$ only accounts for $2.8 \mathrm{Wm}^{-2}$ (Table 3). Like $R_{\text {net }}, H_{\text {net }}$ (Fig. 14a) also appears to be excessive in the models compared to in situ measurements. The strong heat flux is likely associated with the breakdown of the stably stratified boundary layer by winds, which drive a large sensible heat flux toward the surface (e.g., van den Broeke et al. 2005). It is beyond the scope of this study to directly evaluate the surface temperature inversion, but we can infer from the energy budget in Fig. 14 and from evaluations of atmospheric stability in the Arctic (Pithan et al. 2014) that the Antarctic inversion is likely too strong in the CMIP5 models.

Over the ocean in winter, the intermodel spread of $\mathrm{SEF}_{\text {net }}$ is dominated by variations in $\mathrm{HF}_{\text {net }}$, as $R_{\text {net }}$ is relatively small (Fig. 14b). The ensemble mean has a negative bias in $R_{\text {net }}$ of about $8 \mathrm{~W} \mathrm{~m}^{-2}$ with respect to CERES-EBAF (Fig. 15b and Table 3). Similar to the case for land, most of the bias in $\mathrm{LW}_{\text {net }}$ and $R_{\text {net }}$ is attributable to insufficient $\mathrm{LW}_{d}$ (Table 3). Nonetheless, several models simulate reasonable $\mathrm{LW}_{\text {net }}$ values over the ocean (Fig. 14b), within a few watts per meter squared of the observations, whereas on land all of the models clearly have a major bias in $\mathrm{LW}_{\text {net }}$ and $\mathrm{LW}_{d}$.

\section{c. Role of clouds on the surface energy flux}

In nature and in models, clouds have a major impact on the surface radiation budget over the Southern
Ocean during summer by regulating the amount of shortwave radiation reaching the surface. Given that the majority of CMIP5 models underestimate SWCF, we might expect that they also underestimate the longwave effects of clouds. We investigate the role of clouds in the winter surface radiation budget by considering the bottom of atmosphere cloud radiative effect (Stephens et al.

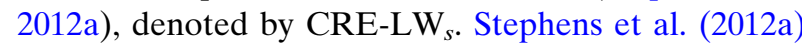
interpret CRE-LW $\mathrm{LW}_{s}$ as the greenhouse effect of clouds and show that it is largest in the high latitudes where the lower atmosphere is quite dry. Field observations demonstrate that the presence of clouds over the AIS can eliminate the negative $R_{\text {net }}$ values that are associated with clear skies and strong temperature inversions (e.g., Warren 1996; van den Broeke et al. 2005; van As et al. 2005; Town et al. 2007).

CMIP5 models have an intermodel range of CRE$\mathrm{LW}_{s}$ over the Southern Ocean of $43 \mathrm{~W} \mathrm{~m}^{-2}$ in JJA (Fig. 16), bracketed by GISS-E2-H (Fig. 16f) and IPSLCM5A-MR (Fig. 16e). The intermodel range over the AIS is much smaller, at $17 \mathrm{~W} \mathrm{~m}^{-2}$ (Figs. 16c,d). The intermodel spread on land is remarkably homogeneous: not a single model is within $10 \mathrm{~W} \mathrm{~m}^{-2}$ of the observations, and all models are negatively biased (Fig. S8 in the supplemental material). Moreover, no model simulates the rich spatial pattern in CRE- $\mathrm{LW}_{s}$ that is evident in CERES-EBAF (Fig. 16a). In CERES-EBAF, CRE$\mathrm{LW}_{s}$ is strongest in regions of relatively steep topography, where clouds can destroy the huge radiation deficits that are maintained by the sensible heat fluxes generated by katabatic winds (van den Broeke et al. 2005). Over regions of less sloping topography, clouds are also quite effective at reducing the stable stratification of the lower atmosphere, thereby limiting the sensible heat fluxes that maintain the radiation deficit (van den Broeke et al. 2005).

Over both ocean and land, the ensemble-mean biases

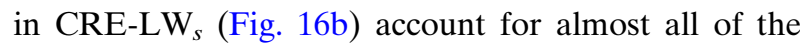
respective biases in $\mathrm{LW}_{d}$ and, by extension, the biases in $R_{\text {net }}$ evident in Figs. 14 and 15. These biases are also quantified in Table 3. For the AIS, CERES-EBAF estimates the CRE- $\mathrm{LW}_{s}$ as $40 \mathrm{Wm}^{-2}$, whereas a typical model value is $20 \mathrm{~W} \mathrm{~m}^{-2}$. This underestimate by a factor of 2 is somewhat surprising given that models do not appear to similarly underestimate the total cloud fraction over Antarctica (Bromwich et al. 2012). However, in addition to cloud fraction, at least three factors contribute to the CRE- $\mathrm{LW}_{s}$ : the cloud-base height and temperature at which the cloud emits radiation to the surface; the opacity of the cloud; and the amount of water vapor below the cloud base, which can absorb and remit the radiation emitted by the cloud, reducing the sensitivity to cloud cover at the surface (Stephens et al. 

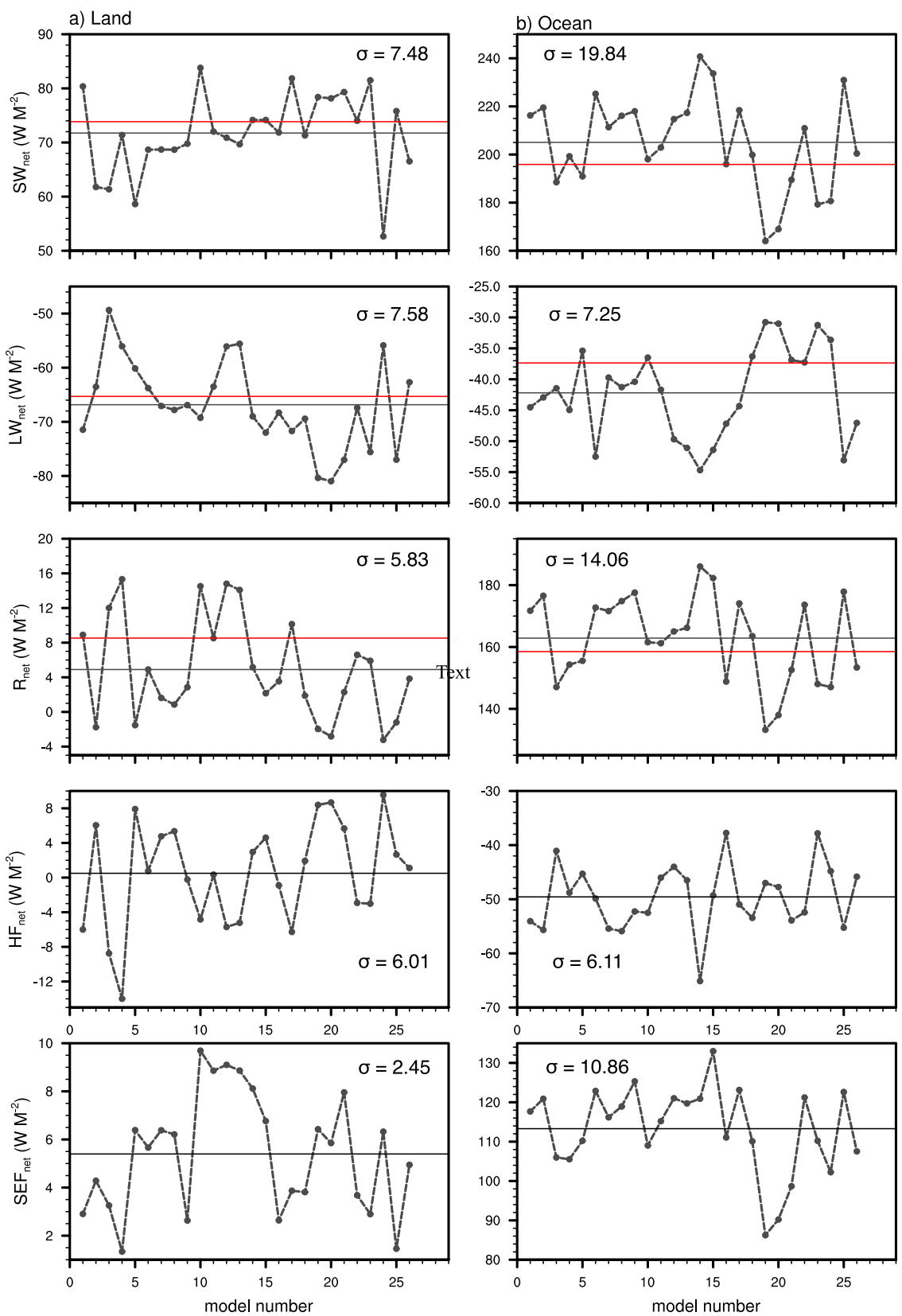

FIG. 13. The terms contributing to the net surface energy flux in DJF in 26 models for (a) land and (b) ocean domains. The ensemble-mean values are indicated by the horizontal gray lines. The observed values for the radiation terms only (from CERES-EBAF) are given as horizontal red lines. The standard deviation $\sigma$ of the model spread is indicated in each panel.

2012a). The dry Antarctic atmosphere, combined with the large temperature difference between the surface and the cloud base, helps to explain the sensitivity of the surface energy budget to cloud cover.

In summer compared to winter, the combination of fewer clouds, more moisture, and weaker surface inversions leads to an expected reduction in the sensitivity of the surface energy budget on the AIS to cloud cover.
This is supported by CERES-EBAF, which shows a summer value of CRE-LW $\mathrm{LW}_{s}$ over land of $29 \mathrm{~W} \mathrm{~m}^{-2}$ (Table 3). However, the summer value of the ensemble mean $\left(22 \mathrm{~W} \mathrm{~m}^{-2}\right)$ is similar to the winter value $\left(19 \mathrm{~W} \mathrm{~m}^{-2}\right)$, and it is weaker than the CERES-EBAF summer value (Table 3). Over the ocean, there is not as much seasonality in CRE-LW ${ }_{s}$ according to CERESEBAF, and the ensemble mean has similar summer and 

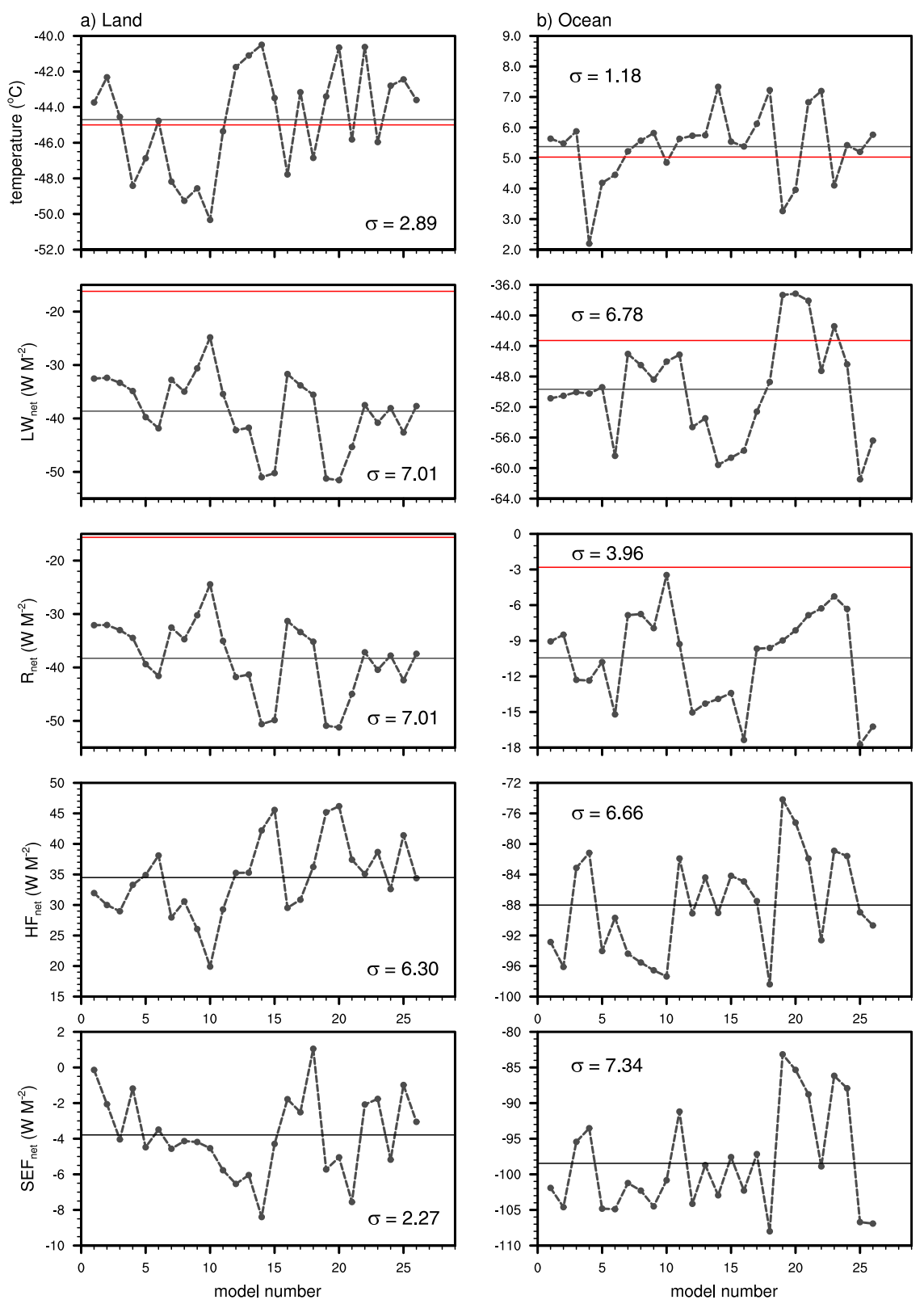

FIG. 14. The SAT and the major terms contributing to the surface energy flux in JJA for 26 models. The ensemble-mean values are given as horizontal gray lines. The observed values (UDEL for SAT over land, ERAI for SAT over ocean, and CERES-EBAF for radiation data) are given as horizontal red lines. The standard deviation $\sigma$ of the model spread is indicated in each panel.

winter biases (Table 3). Summer biases in CRE-LW account for much of the $\mathrm{LW}_{\text {net }}$ biases over the ocean evident in Fig. 13b. For instance, the model with the most negative $\mathrm{LW}_{\text {net }}$ bias, GISS-E2-H, has the largest CRE-LW $\mathrm{L}_{s}$ bias of $-25 \mathrm{~W} \mathrm{~m}^{-2}$. However, this negative longwave bias is swamped by the positive biases in SWCF (Fig. 10b) and SW net (Fig. 13b), making GISSE2-H the most positively biased model in $R_{\text {net }}$ (Fig. 13b).
Bromwich et al. (2012) reviewed the representation of Antarctic clouds in climate models and argued that cloud parameterizations have not been developed with the unique meteorological conditions of Antarctica in mind. Thus, it is not surprising that the CRE- $\mathrm{LW}_{s}$ is not well simulated over Antarctica, but the pervasive nature of the bias in all models is striking. Of course, the bias depends upon the accuracy of the CERES-EBAF data 
a) CERES-EBAF

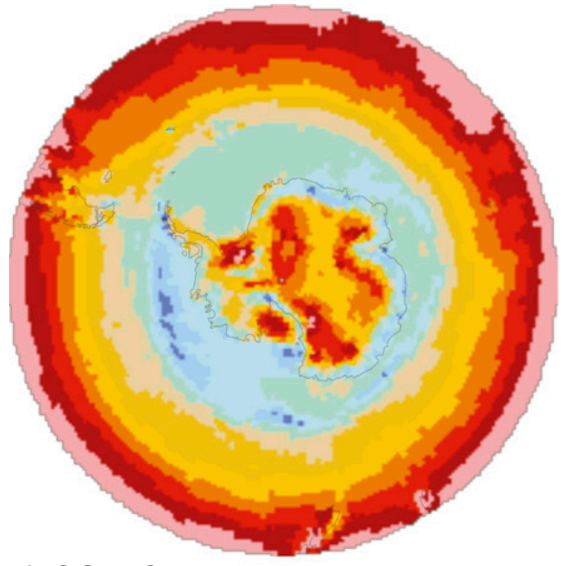

c) CSIRO -8.8(-0.7)

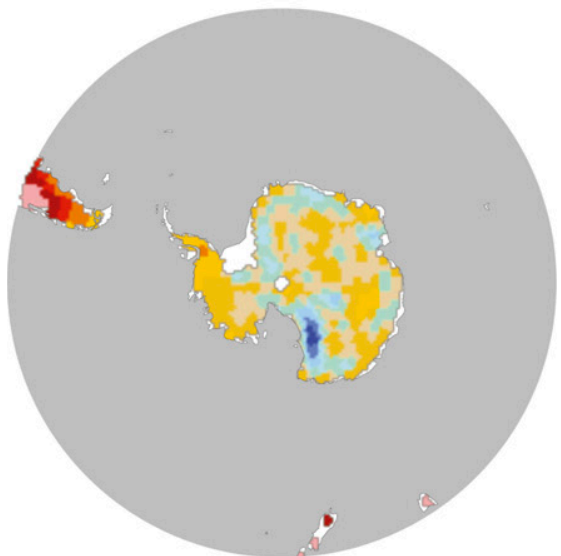

e) CSIRO -8.8(-0.7)

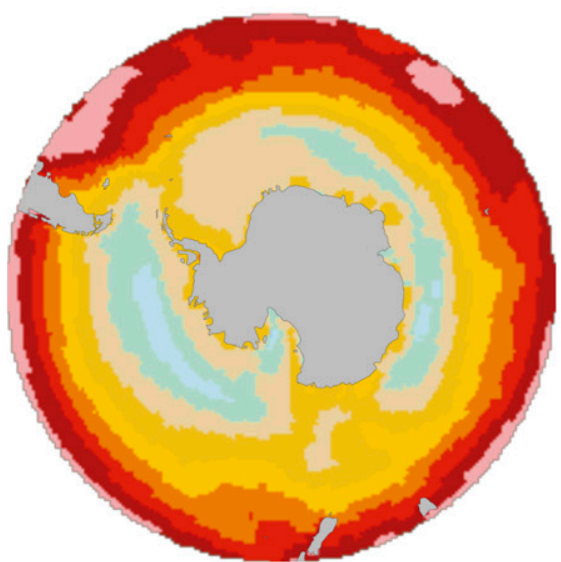

b) ENS -22.6( -7.6)

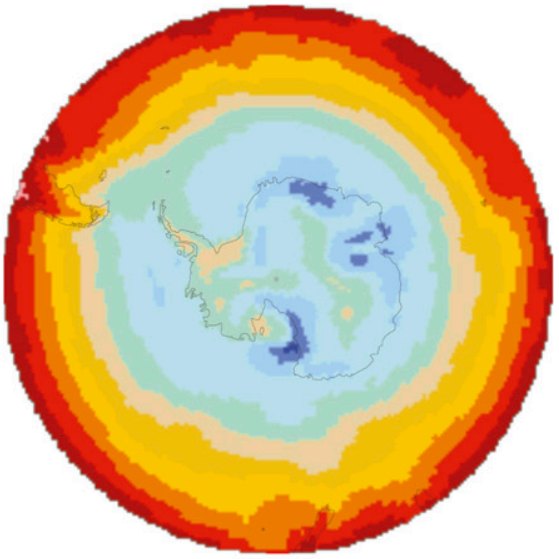

d) IPSL-CM5A-LR -35.6( -5.3)

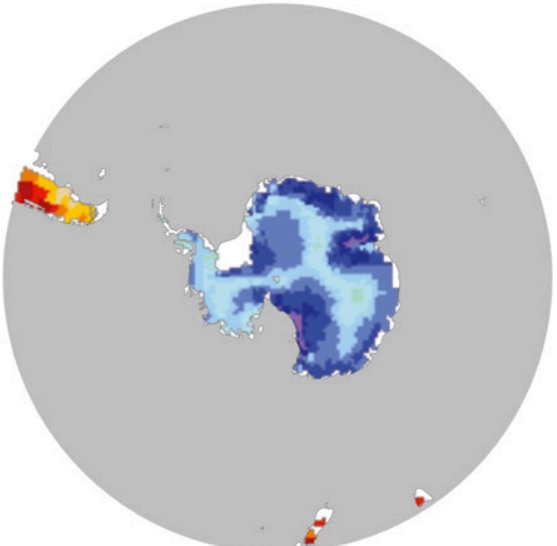

f) MRI-CGCM3 -26.7(-14.9)
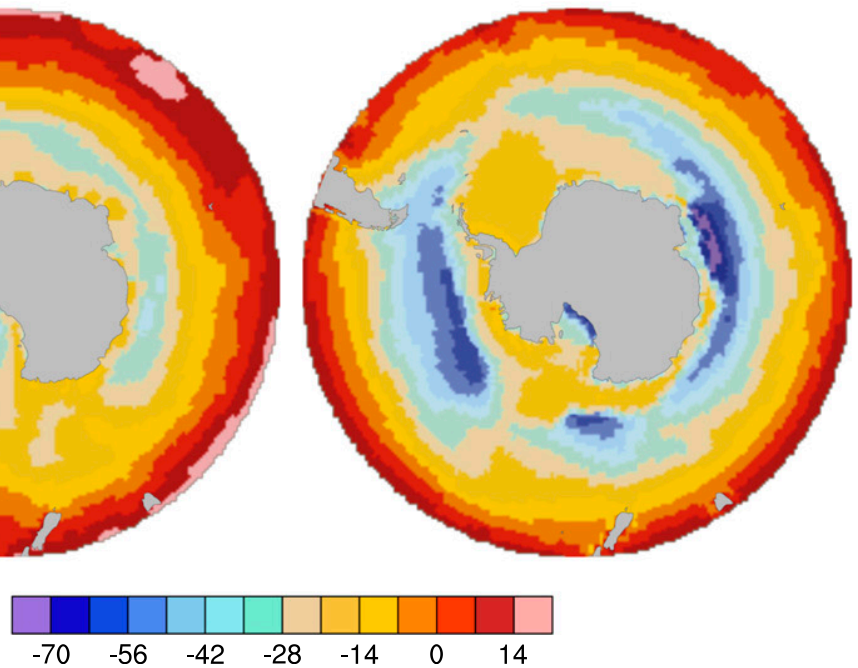

FIG. 15. JJA net surface radiation climatology $\left(\mathrm{W} \mathrm{m}^{-2}\right.$ ) for (a) CERES-EBAF, (b) the 26-model ensemble mean, (c) the model with the largest net radiation over land, (d) the model with the smallest net radiation over land, (e) the model with the largest net radiation over ocean, and (f) the model with the smallest net radiation over ocean. The numbers to the right of the model names give the biases averaged over the land and ocean (in parentheses) domains. 


\section{a) CERES-EBAF}

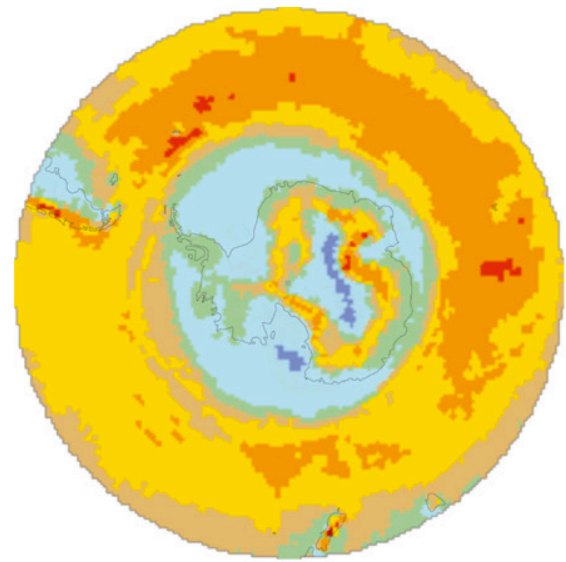

c) bcc-csm1-1 -12.9( -5.1)

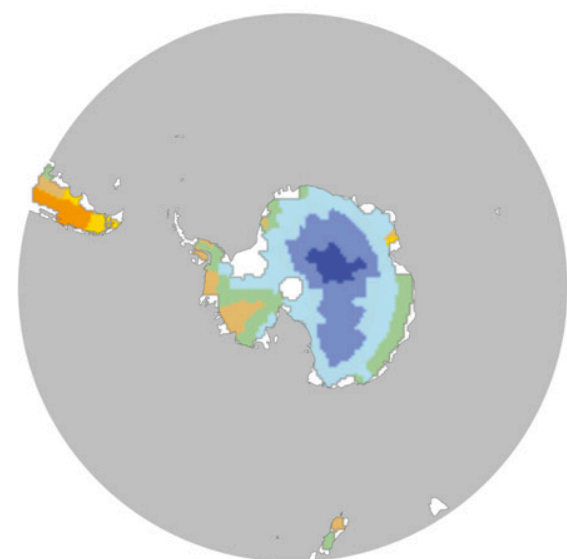

e) IPSL-CM5A-LR -22.7( 14.5)

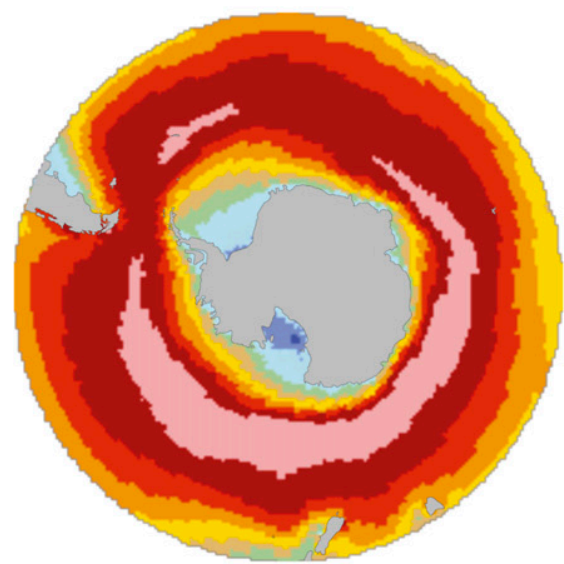

b) ENS -21.0( -5.9)

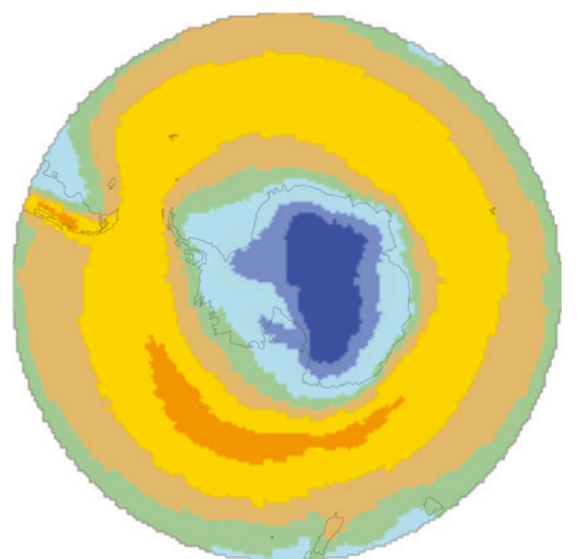

d) MIROC-ESM -30.0( 0.1$)$

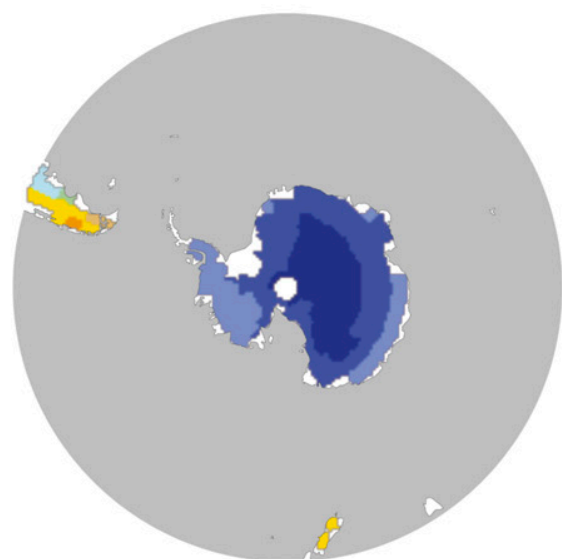

f) GISS-E2-H -25.0(-28.4)

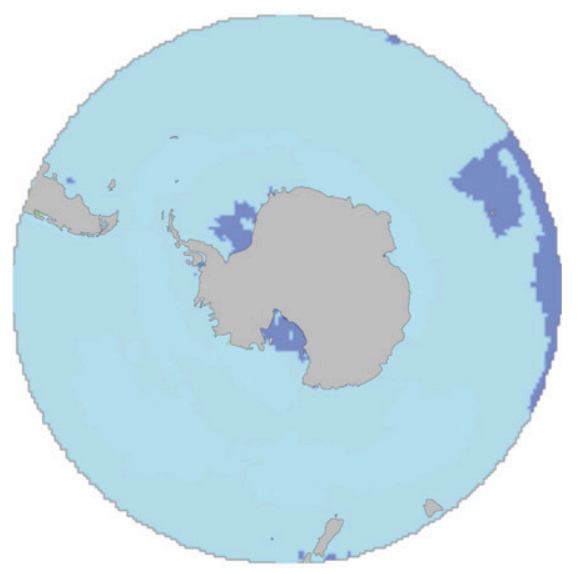

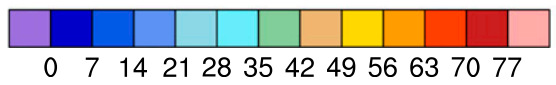

FIG. 16. JJA longwave cloud radiative effect (CRE) at the surface $\left(\mathrm{W} \mathrm{m}^{-2}\right)$ for (a) CERESEBAF, (b) the 26-model ensemble mean, (c) the model with the strongest CRE over land, (d) the model with the weakest CRE over land, (e) the model with the strongest CRE over ocean, and (f) the model with the weakest CRE over ocean. The numbers to the right of the model names give the biases averaged over the land and ocean (in parentheses) domains. 

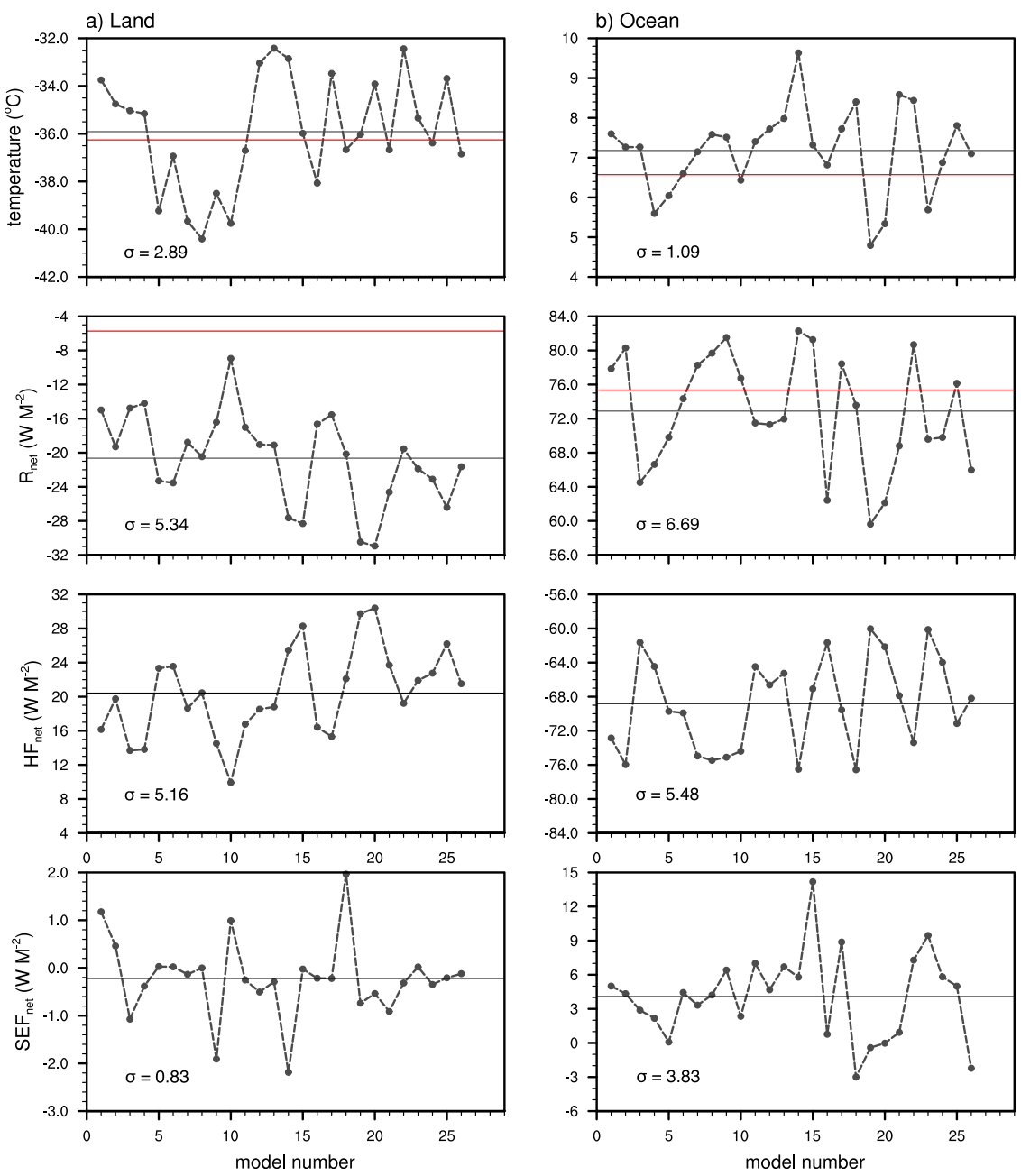

FIG. 17. The SAT and the major terms contributing to the surface energy flux for the annual mean for 26 models. The ensemble-mean values are given as horizontal gray lines. The observed values (UDEL for SAT over land, ERAI for SAT over ocean, and CERES-EBAF for radiation data) are given as horizontal red lines. The standard deviation $(\sigma)$ of the model spread is indicated in each panel.

and its ubiquitous nature may lead one to question these data. We note that the CERES-EBAF data paint a spatial picture of CRE-LW $\mathrm{LW}_{s}$ that is qualitatively in agreement with in situ studies (e.g., van den Broeke et al. 2005). Quantitatively, the CRE-LW $\mathrm{LW}_{s}$ value of $18 \mathrm{~W} \mathrm{~m}^{-2}$ reported by Town et al. (2007) for the South Pole is consistent with the CERES-EBAF data at this location (Fig. 16a). Stephens et al. (2012a) have examined CERES data and find that the global-mean $\mathrm{LW}_{d}$ is consistent with several satellite-based and in situ estimates. Also, for the global mean, the finding that most climate models underestimate $\mathrm{LW}_{d}$ is not new and is supported by several observational datasets (Stephens et al. 2012a,b); our analysis extends this result specifically to Antarctica. Additionally, the association of the largest values of $\mathrm{CRE}-\mathrm{LW}_{s}$ with regions of sloping topography evident in the CERES-EBAF data (Fig. 16a) suggests that spatial resolution may be a limiting factor in the models' representation of CRE-LW .

\section{d. Annual surface energy flux}

To summarize the models' SAT simulations and surface energy budgets, the annual-mean SAT, $R_{\text {net }}, \mathrm{HF}_{\text {net }}$, and $\mathrm{SEF}_{\text {net }}$ are presented in Fig. 17. The ensemble mean is warm-biased by about $0.6^{\circ} \mathrm{C}$ over the ocean and by a smaller, highly uncertain amount over land. The value of $R_{\text {net }}$ is negatively biased in both domains. Over both ocean and land, the annual fluxes of $R_{\text {net }}$ and $\mathrm{HF}_{\text {net }}$ approximately balance in the ensemble mean and in individual models. As clouds have a warming effect on Antarctic surface climate (e.g., Town et al. 2007), a warm (or near zero) bias on the AIS may be unexpected 


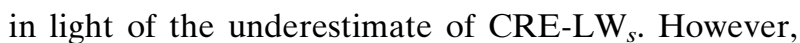
the strong sensible heat fluxes inferred from our analysis compensate for the lack of warming due to clouds. Maps of the ensemble-mean $R_{\text {net }}, \mathrm{HF}_{\text {net }}$, and $\mathrm{SEF}_{\text {net }}$ (Fig. 18) show that $\mathrm{HF}_{\text {net }}$ and $R_{\text {net }}$ almost exactly match each other on land, leading to a spatially homogeneous, nearzero $\mathrm{SEF}_{\text {net }}$ field on land. While the models correctly simulate a near-zero annual $\mathrm{SEF}_{\text {net }}$, the $R_{\text {net }}$ field is too uniformly negative (Fig. 18b) compared to observations (Fig. 18a). Given the strong influence of the surface wind regime on the surface energy budget in Antarctica (e.g., van den Broeke et al. 2005), this could indicate problems with the surface wind climate in models, something that would be interesting to consider in future investigations.

Over the ocean, there is a rich spatial structure in the ensemble mean $\mathrm{HF}_{\text {net }}$ (Fig. 18c) and $\mathrm{SEF}_{\text {net }}$ (Fig. 18d). Considering the poorly constrained heat fluxes over the Southern Ocean (Bourassa et al. 2013), we do not quantify the model biases in $\mathrm{HF}_{\text {net }}$ and $\mathrm{SEF}_{\text {net }}$. However, the spatial patterns are of interest. Generally, less negative values of $\mathrm{HF}_{\text {net }}$ occur near the coast in the cold polar waters with seasonal sea ice cover. The $\mathrm{HF}_{\text {net }}$ contour of $-48 \mathrm{~W} \mathrm{~m}^{-2}$ roughly follows the pathway of the ACC, which separates the cold polar waters from the warmer subtropical waters to the north and is steered by ocean bathymetry (e.g., Martinson 2012). Because of ocean dynamics, the zonal asymmetry of the $\mathrm{SEF}_{\text {net }}$ pattern (Fig. 18d) stands in marked contrast to the more zonally uniform $R_{\text {net }}$ pattern (Fig. 18b). Qualitatively, the ensemble mean $\mathrm{SEF}_{\text {net }}$ pattern agrees well with annual air-sea heat fluxes discussed by Marshall and Speer (2012; see their Fig. 4b) and Cullather and Bosilovich (2012; see their Fig. 6b) using atmospheric reanalyses. The main region of energy gain is the Atlantic sector between $50^{\circ}$ and $60^{\circ} \mathrm{S}$, which is an important region for the conversion of upwelling deep water into less dense Subantarctic Mode Water (Marshall and Speer 2012). Smaller areas of energy gain occur in the Pacific sector at $150^{\circ} \mathrm{E}$ and $180^{\circ}$, which Cullather and Bosilovich (2012) attribute to northward excursions of the ACC around the Pacific-Antarctic Ridge. The region of strong net energy loss around the Antarctic continent is associated with the formation of Antarctic Bottom Water (Marshall and Speer 2012).

\section{Summary and discussion}

This investigation has revealed large and systematic variations in the surface climate of Antarctica and the Southern Ocean simulated by CMIP5 models. This region is vitally important to simulate well given the potential of the AIS to raise sea level, the role of the
Southern Ocean in heat and carbon uptake, and the function of the AIS as a heat sink. We have focused on the SAT as a gauge of model diversity, relating it to the surface energy budget and associated properties including cloud forcing, ice sheet albedo, and turbulent heat fluxes:

1) Most models and the ensemble mean are warmbiased over the Southern Ocean during late summer due to excessive shortwave radiation in early summer and midsummer. Both the ensemble-mean bias and the model spread in SAT are linked with the SWCF.

2) In winter, all models have a strong negative $L_{\text {net }}$ radiation bias over the AIS and most models have a modest negative $\mathrm{LW}_{\text {net }}$ bias over the ocean. In both domains, the deficit in $\mathrm{LW}_{\text {net }}$ is mostly accounted for by a similar deficit in $\mathrm{LW}_{d}$, which can be explained by insufficient cloud radiative forcing, as measured by the longwave cloud radiative effect at the surface. The $\mathrm{LW}_{\text {net }}$ bias over the AIS suggests that the lower atmosphere is too stable in CMIP5 models, similar to reported biases for the Arctic (e.g., Pithan et al. 2014). Relatively coarse model resolution may be a limiting factor in the representation of the longwave cloud radiative effect on the AIS, which observations suggests is strongest in regions of sloping topography. In addition, cloud radiative forcing biases could reflect the fact that most global atmospheric models have not been optimized for the unique meteorological conditions of Antarctica.

3) On the AIS, the winter radiation deficits are largely compensated by turbulent heat fluxes directed toward the surface. These heat fluxes are generally too large compared to reported values, and their warming effect offsets the lack of surface warming due to insufficient cloud radiative forcing. Nonetheless, the models correctly simulate a near-zero annual mean net surface energy flux.

4) Over the Southern Ocean, the ensemble-mean pattern of the annual mean air-sea heat flux is qualitatively consistent with observations, showing a complex pattern associated with the topographic steering of the ACC and the formation of Southern Ocean water masses (Marshall and Speer 2012). The excessive shortwave radiative forcing we have highlighted is consistent with the warm and positive buoyancy biases of these water masses (Sallée et al. 2013).

5) Models exhibit a relatively wide range of surface albedo over the AIS. During summer, the albedo regulates the amount of shortwave radiation absorbed and contributes to the model spread in SAT.

Previous work has focused attention on the biases and model spread in SWCF over the Southern Ocean, 


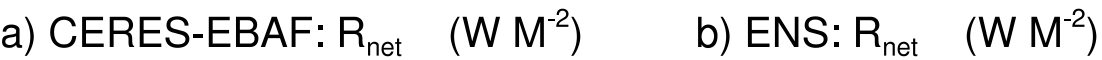
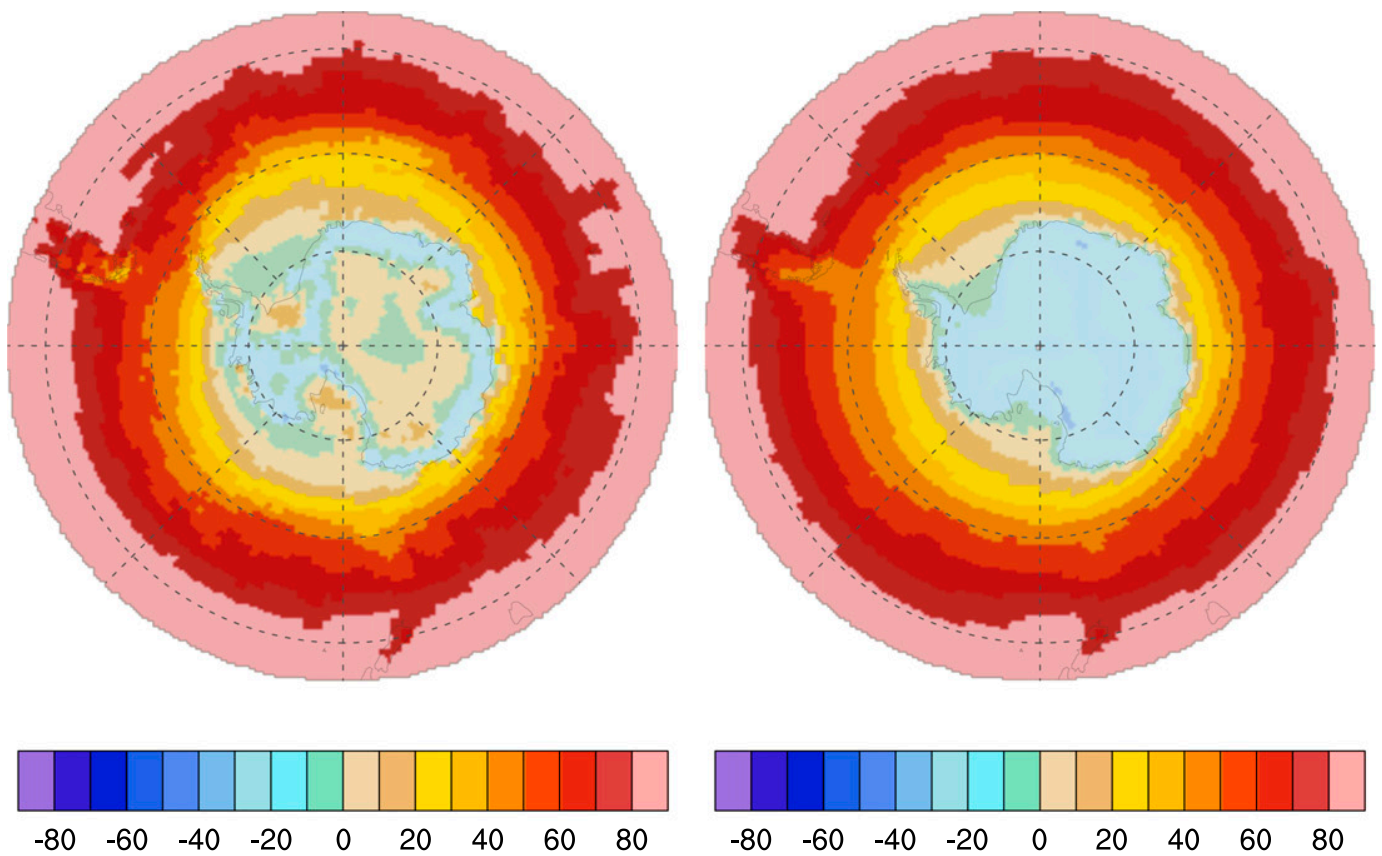

c) ENS: $\mathrm{HF}_{\text {net }}\left(\mathrm{W} \mathrm{M}^{-2}\right)$

d) ENS: SEF $_{\text {net }}\left(\mathrm{W} \mathrm{M}^{-2}\right)$
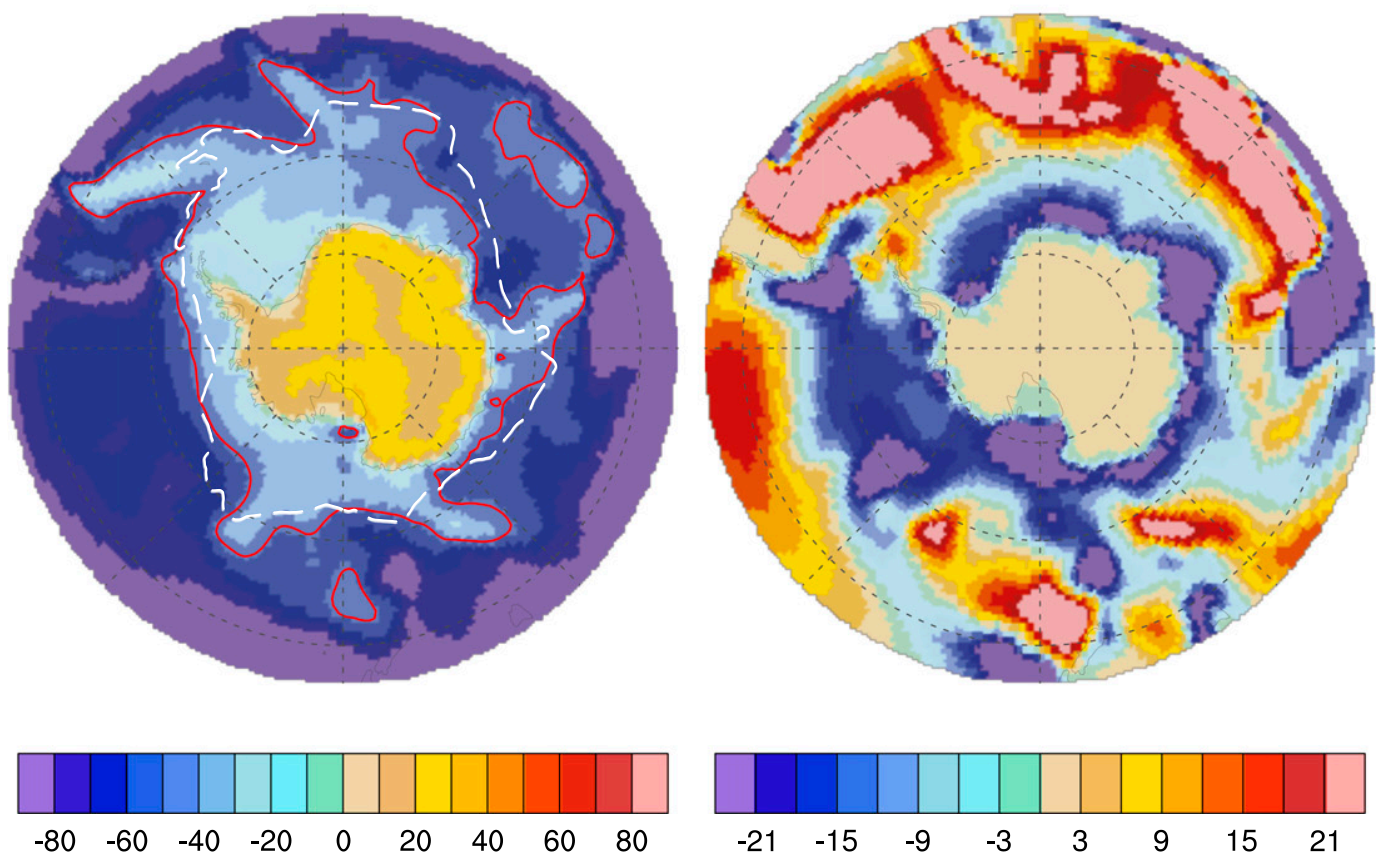

FIG. 18. Annual mean fluxes of (a) net surface radiation in CERES-EBAF, (b) $R_{\text {net }}$ in the ensemble mean, (c) $\mathrm{HF}_{\text {net }}$ (latent + sensible heat flux) in the ensemble mean, and (d) $\mathrm{SEF}_{\text {net }}$ (net radiation + net heat flux) in the ensemble mean. In (c), the red line is the $-48 \mathrm{~W} \mathrm{~m}^{-2} \mathrm{HF}_{\text {net }}$ contour from the models and the white-dashed line is the southernmost ACC front of Orsi et al. (1995). Note that the strip of negative heat fluxes on the Antarctic coast in (d) is an artifact of regridding the models to a common $1^{\circ}$ grid; this does not impact the spatial averages presented in Fig. 17. 
relating it to meridional ocean heat transport (Trenberth and Fasullo 2010), the position of the westerly midlatitude atmospheric jet (Ceppi et al. 2012), and even the existence of the double intertropical convergence zone (Hwang and Frierson 2013). Our study reinforces concerns about SWCF simulations while extending earlier work to explicitly show a significant correlation between the SWCF and model spread in SAT. Further, the lag in the SAT bias follows the maximum bias in radiative forcing by two months, consistent with the climatology and the ocean's heat capacity. We hope that this study directs attention toward additional physical processes and properties, including the longwave cloud radiative effect, the parameterizations of turbulent heat fluxes, and the ice sheet surface albedo. The problems over the ice sheet will be critical to overcome as coupled models begin to include interactive ice sheets (e.g., Lipscomb et al. 2013). There will be low confidence in the projections of these models if the surface forcing is not credible.

We have seen some evidence that models are improving in some aspects of Antarctic and Southern Ocean climate simulations. Using the ASR as a metric of model performance, which relates closely to the SWCF over the ocean and to the ice sheet surface albedo, the best-performing models represent distinct development efforts [see Kay et al. (2012) for CAM5 and Bentsen et al. (2013) for CAM4-Oslo used in NorESM1-M] to improve cloud simulations over a common previousgeneration atmospheric model, the CAM4. Here, we have given several additional targets for model improvements, with potentially broad implications for the climate system as a whole.

In addition to pointing out the limitations of climate models, this study has also illustrated shortcomings of the atmospheric reanalyses and observational products that are commonly used to evaluate models. In particular, there is wide discrepancy in climatological SAT between MERRA and ERAI: in the summer months of December and January, the mean SAT averaged over the AIS differs by about $4^{\circ} \mathrm{C}$. This points to a need to better represent surface processes in the atmospheric reanalyses, as well as for users to exercise caution when interpreting these products. In general, more climatological SAT datasets such as UDEL are needed to facilitate the evaluation of climate models. While many efforts have been made to reconstruct SAT anomalies and trends (e.g., Nicolas and Bromwich 2014), more effort could be focused on the careful construction of the SAT climatology across Antarctica.

Acknowledgments. D. P. Schneider was supported by National Science Foundation (NSF) Grants 1235231 and 1048899. D. B. Reusch was supported by NSF Grant
1043580. We thank the individual climate modeling groups that have produced and made available the model output summarized in Tables 1 and 2 of this paper, as well as the coordination of these experiments by the World Climate Research Programme's Working Group on Coupled Modelling, and the software infrastructure for distributing model data supported by the U.S. Department of Energy's Program for Climate Model Diagnosis and Intercomparison. The primary software used for the analyses and figures presented in this work was the NCAR Command Language (http:// dx.doi.org/10.5065/D6WD3XH5). We thank three anonymous reviewers and the editor, whose constructive comments led to a greatly improved manuscript.

\section{REFERENCES}

Arora, V. K., and Coauthors, 2011: Carbon emission limits required to satisfy future representative concentration pathways of greenhouse gases. Geophys. Res. Lett., 38, L05805, doi:10.1029/2010GL046270.

Bentsen, M., and Coauthors, 2013: The Norwegian Earth System Model, NorESM1-M-Part 1: Description and basic evaluation of the physical climate. Geosci. Model Dev., 6, 687-720, doi:10.5194/gmd-6-687-2013.

Bi, and Coauthors, 2013: The ACCESS coupled model: Description, control climate and evaluation. Aust. Meteor. Oceanogr. J., 63 , $41-64$.

Bintanja, R., G. J. van Oldenborgh, S. S. Drijfhout, B. Wouters, and C. A. Katsman, 2013: Important role for ocean warming and increased ice-shelf melt in Antarctic sea-ice expansion. Nat. Geosci., 6, 376-379, doi:10.1038/ngeo1767.

Bodas-Salcedo, A., K. D. Williams, P. R. Field, and A. P. Lock, 2012: The surface downwelling solar radiation surplus over the Southern Ocean in the Met Office model: The role of midlatitude cyclone clouds. J. Climate, 25, 7467-7486, doi:10.1175/ JCLI-D-11-00702.1.

Böning, C. W., A. Dispert, M. Visbeck, S. R. Rintoul, and F. U. Schwarzkopf, 2008: The response of the Antarctic Circumpolar Current to recent climate change. Nat. Geosci., 1, 864 869, doi:10.1038/ngeo362.

Bourassa, M. A., and Coauthors, 2013: High-latitude ocean and sea ice surface fluxes: Challenges for climate research. Bull. Amer. Meteor. Soc., 94, 403-423, doi:10.1175/BAMS-D-11-00244.1.

Bracegirdle, T. J., and G. J. Marshall, 2012: The reliability of Antarctic tropospheric pressure and temperature in the latest global reanalyses. J. Climate, 25, 7138-7146, doi:10.1175/ JCLI-D-11-00685.1.

Bromwich, D. H., and Coauthors, 2012: Tropospheric clouds in Antarctica. Rev. Geophys., 50, RG1004, doi:10.1029/ 2011RG000363.

Ceppi, P., Y.-T. Hwang, D. M. W. Frierson, and D. L. Hartmann, 2012: Southern Hemisphere jet latitude biases in CMIP5 models linked to shortwave cloud forcing. Geophys. Res. Lett. 39, L19708, doi:10.1029/2012GL053115.

Cullather, R. I., and M. G. Bosilovich, 2012: The energy budget of the polar atmosphere in MERRA. J. Climate, 25, 5-24, doi:10.1175/2011JCLI4138.1.

Dee, D. P., and Coauthors, 2011: The ERA-Interim reanalysis: Configuration and performance of the data assimilation 
system. Quart. J. Roy. Meteor. Soc., 137, 553-597, doi:10.1002/ qj.828.

Ding, Q., E. J. Steig, D. S. Battisti, and J. M. Wallace, 2012: Influence of the tropics on the southern annular mode. J. Climate, 25, 6330-6348, doi:10.1175/JCLI-D-11-00523.1.

Donohoe, A., and D. S. Battisti, 2011: Atmospheric and surface contributions to planetary albedo. J. Climate, 24, 4402-4418, doi:10.1175/2011JCLI3946.1.

Dufour, C. O., J. Le Sommer, J. D. Zika, M. Gehlen, J. C. Orr, P. Mathiot, and B. Barnier, 2012: Standing and transient eddies in the response of the Southern Ocean meridional overturning to the southern annular mode. J. Climate, 25, 6958-6974, doi:10.1175/JCLI-D-11-00309.1.

Dufresne, J.-L., and Coauthors, 2013: Climate change projections using the IPSL-CM5 Earth system model: From CMIP3 to CMIP5. Climate Dyn., 40, 2123-2165, doi:10.1007/ s00382-012-1636-1.

Dunne, J. P., and Coauthors, 2012: GFDL's ESM2 global coupled climate-carbon Earth system models. Part I: Physical formulation and baseline simulation characteristics. J. Climate, $\mathbf{2 5}$, 6646-6665, doi:10.1175/JCLI-D-11-00560.1.

Ekström, M., M. R. Grose, and P. H. Whetton, 2015: An appraisal of downscaling methods used in climate change research Wiley Interdiscip. Rev.: Climatic Change, 6, 301-319, doi:10.1002/wcc.339.

Fan, T., C. Deser, and D. P. Schneider, 2014: Recent Antarctic sea ice trends in the context of Southern Ocean surface climate variations since 1950. Geophys. Res. Lett., 41, 2419-2426, doi:10.1002/2014GL059239.

Flato, G., and Coauthors, 2013: Evaluation of climate models. Climate Change 2013: The Physical Science Basis, T. F. Stocker et al., Eds., Cambridge University Press, 741-866.

Gent, P. R., and Coauthors, 2011: The Community Climate System Model version 4. J. Climate, 24, 4973-4991, doi:10.1175/ 2011JCLI4083.1.

Giorgetta, M. A., and Coauthors, 2013: Climate and carbon cycle changes from 1850 to 2100 in MPI-ESM simulations for the Coupled Model Intercomparison Project phase 5. J. $A d v$. Model. Earth Syst., 5, 572-597, doi:10.1002/jame.20038.

Gordon, A. L., 1981: Seasonality of Southern Ocean sea ice. J. Geophys. Res., 86, 4193-4197, doi:10.1029/JC086iC05p04193.

Gordon, C., C. Cooper, C. A. Senior, H. Banks, J. M. Gregory, T. C. Johns, J. F. B. Mitchell, and R. A. Wood, 2000: The simulation of SST, sea ice extents and ocean heat transports in a version of the Hadley Centre coupled model without flux adjustments. Climate Dyn., 16, 147-168, doi:10.1007/ s003820050010.

Griffies, S. M., and Coauthors, 2011: The GFDL CM3 coupled climate model: Characteristics of the ocean and sea ice simulations. J. Climate, 24, 3520-3544, doi:10.1175/ 2011JCLI3964.1.

Hobbs, W. R., N. L. Bindoff, and M. N. Raphael, 2015: New perspectives on observed and simulated Antarctic sea ice extent trends using optimal fingerprinting techniques. J. Climate, $\mathbf{2 8}$, 1543-1560, doi:10.1175/JCLI-D-14-00367.1.

Holland, P. R., 2014: The seasonality of Antarctic sea ice trends. Geophys. Res. Lett., 41, 4230-4237, doi:10.1002/2014GL060172.

Hurrell, J. W., and Coauthors, 2013: The Community Earth System Model: A framework for collaborative research. Bull. Amer. Meteor. Soc., 94, 1339-1360, doi:10.1175/ BAMS-D-12-00121.1.

Hwang, Y.-T., and D. M. W. Frierson, 2013: Link between the double-intertropical convergence zone problem and cloud biases over the Southern Ocean. Proc. Natl. Acad. Sci. USA, 110, 4935-4940, doi:10.1073/pnas.1213302110.

Jones, P. D., and D. H. Lister, 2014: Antarctic near-surface air temperatures compared with ERA-Interim values since 1979. Int. J. Climatol, 35, 1354-1366. doi:10.1002/joc.4061.

Kay, J. E., and Coauthors, 2012: Exposing global cloud biases in the Community Atmosphere Model (CAM) using satellite observations and their corresponding instrument simulators. J. Climate, 25, 5190-5207, doi:10.1175/JCLI-D-11-00469.1.

Lipscomb, W. H., and Coauthors, 2013: Implementation and initial evaluation of the Glimmer Community Ice Sheet Model in the Community Earth System Model. J. Climate, 26, 7352-7371, doi:10.1175/JCLI-D-12-00557.1.

Loeb, N. G., B. A. Wielicki, D. R. Doelling, G. L. Smith, D. F. Keyes, S. Kato, N. Manalo-Smith, and T. Wong, 2009: Toward optimal closure of the Earth's top-of-atmosphere radiation budget. J. Climate, 22, 748-766, doi:10.1175/2008JCLI2637.1. , S. Kato, W. Su, T. Wong, F. G. Rose, D. R. Doelling, J. R. Norris, and X. Huang, 2012: Advances in understanding top-ofatmosphere radiation variability from satellite observations. Surv. Geophys., 33, 359-385, doi:10.1007/s10712-012-9175-1.

Mahlstein, I., P. R. Gent, and S. Solomon, 2013: Historical Antarctic mean sea ice area, sea ice trends, and winds in CMIP5 simulations. J. Geophys. Res. Atmos., 118, 5105-5110, doi:10.1002/jgrd.50443.

Marshall, J., and K. Speer, 2012: Closure of the meridional overturning circulation through Southern Ocean upwelling. Nat. Geosci., 5, 171-180, doi:10.1038/ngeo1391.

Martin, G. M., and Coauthors, 2011: The HadGEM2 family of Met Office Unified Model climate configurations. Geosci. Model Dev., 4, 723-757, doi:10.5194/gmd-4-723-2011.

Martinson, D. G., 2012: Antarctic Circumpolar Current's role in the Antarctic ice system: An overview. Palaeogeogr. Palaeoclimatol. Palaeoecol., 335-336, 71-74, doi:10.1016/ j.palaeo.2011.04.007.

Masson, D., and R. Knutti, 2011: Climate model genealogy. Geophys. Res. Lett., 38, L08703, doi:10.1029/2011GL046864.

Matsuura, K., and C. J. Wilmott, 2012: Terrestrial air temperature: 1900-2010 gridded monthly time series. [Available online at http://climate.geog.udel.edu/ climate/html_pages/Global2011/ README.GlobalTsT2011.html.]

Meijers, A. J. S., 2014: The Southern Ocean in the Coupled Model Intercomparison Project phase 5. Philos. Trans. Roy. Soc., 372A, 20130296, doi:10.1098/rsta.2013.0296.

Nicolas, J. P., and D. H. Bromwich, 2014: New reconstruction of Antarctic near-surface temperatures: Multidecadal trends and reliability of global reanalyses. J. Climate, 27, 8070-8093, doi:10.1175/JCLI-D-13-00733.1.

Orsi, A. H., T. Whitworth, and W. D. Nowlin, 1995: On the meridional extent and fronts of the Antarctic Circumpolar Current. DeepSea Res. I, 42, 641-673, doi:10.1016/0967-0637(95)00021-W.

Parish, T. R., and D. H. Bromwich, 2007: Reexamination of the near-surface airflow over the Antarctic continent and implications on atmospheric circulations at high southern latitudes. Mon. Wea. Rev., 135, 1961-1973, doi:10.1175/ MWR3374.1.

Phipps, S. J., L. D. Rotstayn, H. B. Gordon, J. L. Roberts, A. C. Hirst, and W. F. Budd, 2011: The CSIRO Mk3L climate system model version 1.0-Part 1: Description and evaluation. Geosci. Model Dev., 4, 483-509, doi:10.5194/gmd-4-483-2011.

Pielke, R. A., and R. L. Wilby, 2012: Regional climate downscaling: What's the point? Eos, Trans. Amer. Geophys. Union, 93, 5253, doi:10.1029/2012EO050008. 
Pithan, F., B. Medeiros, and T. Mauritsen, 2014: Mixed-phase clouds cause climate model biases in Arctic wintertime temperature inversions. Climate Dyn., 43, 289-303, doi:10.1007/ s00382-013-1964-9.

Previdi, M., K. L. Smith, and L. M. Polvani, 2013: The Antarctic atmospheric energy budget. Part I: Climatology and intraseasonal-to-interannual variability. J. Climate, 26, 64066418, doi:10.1175/JCLI-D-12-00640.1.

Qu, X., and A. Hall, 2005: Surface contribution to planetary albedo variability in cryosphere regions. J. Climate, 18, 5239-5252, doi:10.1175/JCLI3555.1.

Rienecker, M. M., and Coauthors, 2011: MERRA: NASA's Modern-Era Retrospective Analysis for Research and Applications. J. Climate, 24, 3624-3648, doi:10.1175/ JCLI-D-11-00015.1.

Rintoul, S. R., and A. C. Naveira Garabato, 2013: Dynamics of the Southern Ocean circulation. Ocean Circulation and Climate: $A$ 21st Century Perspective, 2nd ed., G. Siedler et al., Eds, Academic Press, 471-492.

Sallée, J.-B., K. G. Speer, and S. R. Rintoul, 2010: Zonally asymmetric response of the Southern Ocean mixed-layer depth to the southern annular mode. Nat. Geosci., 3, 273-279, doi:10.1038/ngeo812.

, E. Shuckburgh, N. Bruneau, A. J. S. Meijers, T. J. Bracegirdle, Z. Wang, and T. Roy, 2013: Assessment of Southern Ocean water mass circulation and characteristics in CMIP5 models: Historical bias and forcing response. J. Geophys. Res. Oceans, 118, 1830-1844, doi:10.1002/jgrc.20135.

Schmidt, G. A., and Coauthors, 2006: Present-day atmospheric simulations using GISS ModelE: Comparison to in situ, satellite, and reanalysis data. J. Climate, 19, 153-192, doi:10.1175/ JCLI3612.1.

Schneider, D. P., C. Deser, and T. Fan, 2015: Comparing the impacts of tropical SST variability and polar stratospheric ozone loss on the Southern Ocean westerly winds. J. Climate, 28, 9350-9372, doi:10.1175/JCLI-D-15-0090.1.

Staten, P. W., J. J. Rutz, T. Reichler, and J. Lu, 2012: Breaking down the tropospheric circulation response by forcing. Climate Dyn., 39, 2361-2375, doi:10.1007/s00382-011-1267-y.

Stephens, G. A., M. Wild, P. W. Stackhouse, T. L'Ecuyer, S. Kato, and D. S. Henderson, 2012a: The global character of the flux of downward longwave radiation. J. Climate, 25, 2329-2340, doi:10.1175/JCLI-D-11-00262.1.

_ - and Coauthors, 2012b: An update on Earth's energy balance in light of the latest global observations. Nat. Geosci., 5, 691696, doi:10.1038/ngeo1580.

Taylor, K. E., 2001: Summarizing multiple aspects of model performance in a single diagram. J. Geophys. Res., 106, 71837192, doi:10.1029/2000JD900719.

- R. J. Stouffer, and G. A. Meehl, 2012: An overview of CMIP5 and the experiment design. Bull. Amer. Meteor. Soc., 93, 485498, doi:10.1175/BAMS-D-11-00094.1.

Thompson, D. W. J., S. Solomon, P. J. Kushner, M. H. England, K. M. Grise, and D. J. Karoly, 2011: Signatures of the Antarctic ozone hole in Southern Hemisphere surface climate change. Nat. Geosci., 4, 741-749, doi:10.1038/ngeo1296.
Town, M. S., V. P. Walden, and S. G. Warren, 2007: Cloud cover over the South Pole from visual observations, satellite retrievals, and surface-based infrared radiation measurements. J. Climate, 20, 544-559, doi:10.1175/JCLI4005.1.

Trenberth, K. E., and J. T. Fasullo, 2010: Simulation of present-day and twenty-first-century energy budgets of the southern oceans. J. Climate, 23, 440-454, doi:10.1175/2009JCLI3152.1.

_ , Y. Zhang, J. T. Fasullo, and S. Taguchi, 2015: Climate variability and relationships between top-of-atmosphere radiation and temperatures on Earth. J. Geophys. Res. Atmos., 120, 3642-3659. doi:10.1002/2014JD022887.

Turner, J., T. J. Bracegirdle, T. Phillips, G. J. Marshall, and J. S. Hosking, 2013: An initial assessment of Antarctic sea ice extent in the CMIP5 models. J. Climate, 26, 1473-1484, doi:10.1175/JCLI-D-12-00068.1.

van As, D., M. van den Broeke, C. Reijmer, and R. van de Wal, 2005: The summer surface energy balance of the high Antarctic plateau. Bound.-Layer Meteor., 115, 289-317, doi:10.1007/s10546-004-4631-1.

van den Broeke, M. R., 2004: On the role of Antarctica as heat sink for the global atmosphere. J. Phys. IV, 121, 115-124, doi: 10.1051/ jp4:2004121006.

_ C. Reijmer, D. van As, R. van de Wal, and J. Oerlemans, 2005: Seasonal cycles of Antarctic surface energy balance from automatic weather stations. Ann. Glaciol., 41, 131-139, doi:10.3189/172756405781813168.

Voldoire, A., and Coauthors, 2013: The CNRM-CM5.1 global climate model: Description and basic evaluation. Climate Dyn., 40, 2091-2121, doi:10.1007/s00382-011-1259-y.

Volodin, E. M., N. A. Dianskii, and A. V. Gusev, 2010: Simulating present-day climate with the INMCM4.0 coupled model of the atmospheric and oceanic general circulations. Izv., Atmos. Ocean. Phys., 46, 414-431, doi:10.1134/S000143381004002X.

Warren, S. G., 1996: Antarctica. Encyclopedia of Weather and Climate, Vol. 1, Oxford University Press, 32-39.

Watanabe, M., and Coauthors, 2010: Improved climate simulation by MIROC5: Mean states, variability, and climate sensitivity. J. Climate, 23, 6312-6335, doi:10.1175/2010JCLI3679.1.

Watanabe, S., and Coauthors, 2011: MIROC-ESM 2010: Model description and basic results of CMIP5-20c3m experiments. Geosci. Model Dev., 4, 845-872, doi:10.5194/gmd-4-845-2011.

Wei, T., and Coauthors, 2012: Developed and developing world responsibilities for historical climate change and $\mathrm{CO}_{2}$ mitigation. Proc. Natl. Acad. Sci. USA, 109, 12911-12915, doi:10.1073/pnas.1203282109.

Wu, T., and Coauthors, 2014: An overview of BCC climate system model development and application for climate change studies. Acta Meteor. Sin., 28, 34-56, doi:10.1007/ s13351-014-3041-7.

Yukimoto, S., and Coauthors, 2012: A new global climate model of the Meteorological Research Institute: MRI-CGCM3Model description and basic performance. J. Meteor. Soc. Japan, 90A, 23-64, doi:10.2151/jmsj.2012-A02.

Zunz, V., H. Goosse, and F. Massonnet, 2013: How does internal variability influence the ability of CMIP5 models to reproduce the recent trend in Southern Ocean sea ice extent? Cryosphere, 7, 451-468, doi:10.5194/tc-7-451-2013. 